Revista lus et Praxis, Año 22, No 1, 2016, pp. 227 - 270

ISSN 0717 - 2877

Universidad de Talca - Facultad de Ciencias Jurídicas y Sociales

La restitución de ganancias ilícitas y la acción del provecho por dolo ajeno

Alberto Pino Emhart

Trabajo recibido el 10 de diciembre de 2014 y aprobado el 19 de octubre de 2015

\title{
La restitución de ganancias ilícitas y la acción del provecho por dolo ajeno*
}

\section{THE RESTITUTION OF UNJUST GAINS AND THE DISGORGEMENT \\ OF PROFITS GAINED BY THIRD-PARTY'S FRAUD CLAIM}

\section{Alberto Pino EMhart*}

\begin{abstract}
RESUMEN
Este trabajo persigue situar la acción restitutoria de los artículos 1458 y 2316 del Código Civil de Chile dentro del marco teórico de la restitución de ganancias obtenidas ilícitamente, a propósito de los recientes casos Inverlink. Este marco teórico se formula en base a la doctrina y jurisprudencia anglosajonas. Se argumenta que la acción sería una expresión del principio general que justifica la restitución de ganancias ilícitas, según el cual la comisión de un ilícito con dolo no puede tener las mismas consecuencias que la comisión de un ilícito meramente negligente.
\end{abstract}

\section{ABSTRACT}

This work seeks to encapsulate the restitutionary claim established by articles 1458 and 2316 of the Chilean Civil Code within the theoretical framework of the disgorgement of unjust gains, in the context of the recent Inverlink cases. This framework is elaborated based on common law authors and cases. It is argued that the restitutionary claim is an application of the principle that justifies gain-based damages in general, according to which an intentional wrong cannot have the same consequences than a merely negligent wrong.

Palabras Clave

Enriquecimiento injustificado, Justicia correctiva, Ganancias ilícitas,

Responsabilidad extracontractual, Responsabilidad contractual

KEYWORDS

Unjust enrichment, Corrective justice, Unjust gains, Restitution for wrongs,

Restitution for breach of contract

\footnotetext{
* Para la redacción del presente trabajo, me he visto (injustificadamente) enriquecido por diversas conversaciones con Rodrigo Momberg Uribe y Daniel Peñailillo Arévalo, quienes siempre me aportaron con agudas y pertinentes observaciones relativas a este tema. Un especial agradecimiento merece el primero de ellos, con quien inicialmente surgió la idea de escribir este artículo. También agradezco los agudos comentarios que recibí a borradores previos de este trabajo de Cristián Banfi del Río, Arturo lbáñez León y Esteban Pereira Fredes. Agradezco también los comentarios de dos revisores anónimos. Cualquier error que permanezca en el texto es de exclusiva responsabilidad mía. Las traducciones de los textos de doctrina y jurisprudencia en inglés son mías, a menos que se indique lo contrario en la información bibliográfica.

** Profesor de Derecho Civil y Teoría del Derecho, Universidad Adolfo Ibáñez. Licenciado en Ciencias Jurídicas y Sociales, y Magíster en Derecho con mención en Derecho Privado, Universidad de Chile; LL.M., Duke University; Doctor en Derecho (D.Phil), University of Oxford. Dirección postal: Diagonal Las Torres 2640, Oficina 218-B, Peñalolén, Santiago. Correo electrónico: alberto.pino@uai.cl.
} 


\section{Introducción}

Pedro utiliza el caballo Rocinante de propiedad de Juan sin pedirle a este su autorización. Pedro lo utiliza para participar en una carrera y obtiene una ganancia producto de ello. Posteriormente, Pedro le devuelve el caballo a Juan sin que este se dé cuenta. Rocinante no sufrió daño alguno por participar en la carrera, por lo cual Juan tampoco sufrió perjuicio alguno. ¿ Otorga el sistema jurídico alguna acción para que Juan pueda recuperar de Pedro la ganancia que este obtuvo ilícitamente, mediante un uso no autorizado de propiedad ajena? La situación claramente se encuentra fuera del ámbito de la responsabilidad extracontractual, puesto que Juan no ha sufrido daño alguno. En el ejemplo, Pedro y Juan no tienen una relación contractual previa. ¿Qué pasaría si ambos tienen una relación contractual? Supongamos ahora que Carlos, contratista de la empresa Cola-Cola (productora de bebidas de fantasía) vende la fórmula secreta de una de sus bebidas a su competidor Pep-Cola, violando el contrato suscrito por ambos. Pep-Cola intenta reproducir la fórmula de la popular bebida, pero no logra elaborar un producto con el mismo sabor (tal vez porque faltaba un ingrediente que Carlos desconocía, o porque la fórmula vendida contenía términos demasiado técnicos que Pep-Cola no logra descifrar). Supongamos, en consecuencia, que Cola-Cola no sufre daño alguno con el incumplimiento del contrato, o al menos no le es posible probar que ha ocurrido un perjuicio. ¿Es posible para Cola-Cola solicitar la restitución de las ganancias obtenidas por Carlos con la venta de la fórmula secreta, en contravención al contrato suscrito por las partes? Nuevamente, la situación escapa del ámbito de la responsabilidad contractual, puesto que Cola-Cola no ha sufrido daño alguno por el que pueda demandar a Carlos; solo existe una ganancia obtenida ilícitamente por Carlos al incumplir su contrato. Solo es posible recurrir al principio del enriquecimiento injustificado para remediar este tipo de situaciones.

Desde hace un tiempo ya que la doctrina chilena, a través de autores como Fernando Fueyo Laneri y Daniel Peñailillo Arévalo, han reconocido la existencia del principio general que prohíbe el enriquecimiento injustificado (en adelante, 'enriquecimiento injustificado') dentro de nuestro ordenamiento jurídico privado, aun cuando este no se encuentre consagrado expresamente en el Código Civil chileno. ${ }^{1}$ Estos autores sugieren que el enriquecimiento injustificado constituye una fuente autónoma de obligaciones. Ello implica que el principio no solo constituye el fundamento de una serie de normas específicas del Código Civil que tradicionalmente se han considerado como expresiones del mismo, sino que además se establece la posibilidad de invocar el enriquecimiento injustificado como una acción general autónoma. El hecho que el Código Civil no

1 Fueyo (1990), pp. 433 y ss.; Peñailillo (1996), pp. 29 y ss. 
contemple esta fuente de obligaciones en forma expresa no debiera mermar la posibilidad de que la doctrina y jurisprudencia chilenas la reconozca. ${ }^{2}$ Algo similar ha ocurrido con el desarrollo de la indemnización del daño moral en el ámbito contractual y extracontractual.

Sin embargo, el objeto del presente trabajo no es el principio del enriquecimiento injustificado en general, sino una aplicación específica de este. Dicha aplicación dice relación con la restitución de aquellas ganancias que han sido obtenidas ilícitamente, ya sea mediante la comisión de un ilícito civil extracontractual o de un incumplimiento contractual. Si bien el ordenamiento jurídico chileno no contempla una norma general al respecto, los artículos 1458 y 2316 del Código Civil establecen una acción restitutoria poco estudiada por la doctrina chilena que constituye, a mi juicio, una expresión de este corolario del enriquecimiento injustificado. Señala el inciso $2^{\circ}$ del artículo 1458 que "el dolo da lugar solamente a la acción de perjuicios contra la persona o personas que lo han fraguado o que se han aprovechado de él; contra las primeras por el total valor de los perjuicios, y contra las segundas hasta concurrencia del provecho que han reportado del dolo". Mientras que el inciso $2^{\circ}$ del artículo 2316 señala que "el que recibe provecho del dolo ajeno, sin ser cómplice en él, sólo es obligado hasta concurrencia de lo que valga el provecho". Ambas disposiciones establecen una acción en beneficio de quien ha sido víctima de un acto doloso para obtener la restitución de las ganancias que ha obtenido un tercero que no ha participado en la comisión del dolo.

El contexto de los casos Inverlink recientemente resueltos por la Corte Suprema constituye una instancia ideal para la reflexión acerca de esta acción. ${ }^{3}$ Los casos tienen que ver con la litigación desarrollada a partir de uno de los grandes escándalos financieros de los últimos tiempos en Chile. Se trata de una acción concertada por ejecutivos de la empresa Inverlink y funcionarios de la Corporación Nacional de Fomento de la Producción (Corfo), en la cual se sustrajeron instrumentos financieros de largo plazo de Corfo para financiar operaciones de corto plazo de Inverlink. Sin embargo, la operación fue descubierta,

\footnotetext{
2 Sin perjuicio de que pueda deducirse su existencia como fuente de obligaciones del artículo 1437 del Código Civil, cuando señala que las obligaciones pueden nacer "de un hecho voluntario de la persona que se obliga, como en la aceptación de una herencia o legado y en todos los cuasicontratos". El enriquecimiento injustificado podría considerarse como fuente de las obligaciones teniendo en cuenta que las hipótesis mencionadas por la norma constituirían solo ejemplos de hechos voluntarios que generan obligaciones.

3 Para efectos de facilitar la discusión (y porque escapa del objetivo de este trabajo hacer un exhaustivo análisis de todas las sentencias dictadas hasta la fecha), en mi análisis me concentraré en dos sentencias: Corte Suprema, Rol № 4871-2012, de 30 de septiembre de 2013, y Corte Suprema, Rol № 6302-2010, de 30 de enero de 2013.
} 
generando desconfianza en los inversionistas. Como consecuencia de ello, Inverlink sufrió numerosos rescates y retiros por parte de sus inversionistas, produciéndose una verdadera corrida financiera. Los retiros fueron financiados utilizando los instrumentos financieros de Corfo. Con posterioridad, Inverlink fue declarada en quiebra, siendo en la práctica imposible para Corfo recuperar el valor de los instrumentos sustraídos (ascendentes a la suma de \$26.656.468.000). La Corfo no solo persiguió la responsabilidad penal de quienes participaron en la comisión del fraude, sino que también demandó a las empresas e instituciones (algunas de ellas municipalidades) que recibieron los pagos de Inverlink con los instrumentos de Corfo obtenidos ilícitamente. Estas demandas se fundaron en los artículos 1458 y 2316 del Código Civil.

Mi propósito no consiste en comentar pormenorizadamente todos los puntos de interés que tienen estas sentencias. Desde luego, ellas plantean diversos temas que son dignos de un análisis más profundo. Por ejemplo, aspectos interesantes para estudiar $-y$ que fueron discutidos en el transcurso de estos litigios- son la definición de lo que constituye provecho o ganancia para dar lugar a la acción del artículo 2316 del Código Civil, y la forma de computar el plazo de prescripción de la acción. Sin entrar en estos debates, mi objetivo aquí consiste en situar la acción de los artículos 1458 y 2316 del Código Civil dentro del marco teórico amplio de la restitución de ganancias obtenidas ilícitamente. Dicho marco teórico será elaborado sobre la base de sus fundamentos normativos desarrollados en el ámbito del derecho anglosajón. ${ }^{4}$ Con ello, pretendo demostrar que esta acción no reviste una naturaleza tan excepcional como se señala normalmente, sino que sería una expresión del principio según el cual la comisión de un ilícito civil con dolo no puede tener las mismas consecuencias que la comisión de un ilícito civil sin dolo. ${ }^{5}$ De lo anterior, argumentaré que fluye también la idea de que un incumplimiento contractual doloso no puede tener las mismas consecuencias que un incumplimiento contractual sin dolo. Asimismo, pretendo también demostrar que, teniendo en cuenta el fundamento normativo de la restitución de ganancias ilícitas, se desprende que no es compatible la interposición conjunta de la acción de los artículos 1458 y 2316 del

\footnotetext{
${ }^{4}$ El concentrarme en la literatura del derecho anglosajón es una opción metodológica del presente trabajo. Ello no obsta a que pueda realizarse un trabajo similar desde la perspectiva de otras jurisdicciones.

${ }^{5}$ Este principio ha sido discutido en la doctrina chilena mayormente en el ámbito de la responsabilidad contractual, a propósito del artículo 1558 del Código Civil. Por ejemplo en Corral (2010) Domínguez (2000). Sin embargo, BARROS (2006), pp. 404 y 5; BANFI (2012), extienden la aplicación de este principio para el ámbito de la responsabilidad extracontractual. A pesar de que un incumplimiento contractual constituye igualmente un ilícito civil, para efectos de simplificar la discusión me referiré en adelante a los ilícitos civiles extracontractuales como 'ilícitos civiles', a menos que se indique expresamente que me refiero tanto a los ilícitos extracontractuales como contractuales.
} 
Código Civil con una (eventual) acción indemnizatoria por el mismo hecho. Una conclusión contraria implicaría efectuar un doble pago para la víctima.

Para cumplir estos objetivos, se plantea el siguiente plan de trabajo. La segunda sección de esta contribución analiza la justificación moral de la restitución de ganancias ilícitas. En particular, se discute si el principio de justicia correctiva que la literatura especializada normalmente asocia al derecho privado puede justificar estos mecanismos restitutorios. La conclusión es que parece inevitable la necesidad de recurrir a consideraciones de carácter disuasivo para su justificación. La tercera sección del trabajo aborda la restitución de ganancias ilícitas obtenidas como consecuencia de la comisión de un ilícito civil extracontractual, principalmente relacionados con usos indebidos de propiedad ajena (que corresponde a nuestro primer ejemplo). La discusión se nutre de la jurisprudencia del common law sobre la materia, planteando hipótesis para resolver el problema en el derecho chileno. Luego, la cuarta sección analiza el problema en el contexto de la responsabilidad contractual. La pregunta es si es posible establecer mecanismos de restitución de ganancias obtenidas como consecuencia de un incumplimiento contractual. La sección también se nutre de la jurisprudencia del common law al respecto, y se abre la posibilidad de contemplar este mecanismo restitutorio en el derecho chileno. La quinta sección aborda la acción chilena del provecho por dolo ajeno de los artículos 1458 y 2316 como un mecanismo específico de restitución de ganancias ilícitas. Se defiende la postura recientemente acogida por la Corte Suprema y el Tribunal Constitucional, según la cual la naturaleza jurídica de la acción es restitutoria. Teniendo en cuenta la discusión acerca de los fundamentos normativos de la sección segunda, se sostiene que la acción se justifica sobre la base de consideraciones principalmente disuasivas. Finalmente, la sexta sección pretende resolver el problema de la concurrencia de acciones restitutorias e indemnizatorias respecto a un mismo hecho ilícito. Se sostiene que el demandante debe elegir entre ambas vías, ya que de lo contrario se produciría un doble pago para la víctima. Ello también es aplicable a la acción del provecho por dolo ajeno.

\section{El enriquecimiento injustificado y la justicia correctiva}

\subsection{La justicia correctiva como fundamento normativo del derecho privado}

No debiera sorprender que para muchos el fundamento de una acción para obtener la restitución de las ganancias obtenidas ilícitamente resida en la noción de justicia correctiva. ${ }^{6}$ Desde luego, es innegable que este principio cumple un

\footnotetext{
${ }^{6}$ Por ejemplo, señala Enrique Barros Bourie que "la reparación debe seguir en estos casos un criterio de justicia correctiva, que resulte consistente por analogía con las normas del derecho civil". BARROS (2006), p. 933.
} 
rol fundamental en el derecho privado. Incluso para algunos, el derecho privado es y solo debe ser una expresión de la justicia correctiva. ${ }^{7}$ La concepción fundada en justicia correctiva del derecho privado captura acertadamente el carácter transaccional de esta práctica jurídica, justificando al mismo tiempo su estructura bilateral, entre demandante y demandado, agente del daño y víctima, o entre las partes contratantes. Siguiendo a Weinrib, podemos sostener que esta noción de 'correlatividad' ocupa un lugar central en el concepto de justicia correctiva. ${ }^{8}$

Sin embargo, el desarrollo de la discusión académica acerca de los fundamentos del derecho privado ha ido generando alguna desconfianza en torno al principio de justicia correctiva, tanto en su rol explicativo como justificatorio. Por ejemplo, en su rol explicativo se ha señalado que la noción de justicia correctiva es deficiente para dar cuenta de aspectos importantes de los sistemas de responsabilidad extracontractual del common law. John Goldberg y Benjamin Zipursky prefieren la noción de 'recurso civil' [civil recourse] por sobre la de justicia correctiva, lo cual permite explicar la variedad de mecanismos de reparación que los sistemas de responsabilidad extracontractual del common law establecen para remediar la comisión de ilícitos civiles, mecanismos que no necesariamente se traducen en la indemnización de perjuicios. ${ }^{9}$ Por ejemplo, estos autores destacan la existencia en el common law de indemnización de perjuicios 'nominales' [nominal damages] (que no tienen valor económico significativo), o los daños punitivos, ${ }^{10}$ que no pueden ser explicados por la justicia correctiva. Si bien nuestro ordenamiento jurídico no contempla expresamente la existencia de daños punitivos, lo cierto es que podemos encontrar elementos punitivos dentro del derecho privado que la justicia correctiva y su noción de correlatividad no pueden explicar. Así, en el contexto de la avaluación del daño moral, nuestros tribunales han recurrido constantemente a criterios punitivos, sin perjuicio de lo discutible que pueda resultar esta práctica. ${ }^{11}$ También podemos mencionar en el ámbito contractual la existencia de la cláusula penal, en aquellos casos en que opera como una sanción al incumplimiento de contrato y no como una avaluación anticipada de perjuicios. ${ }^{12} \mathrm{Y}$ en doctrina nacional,

\footnotetext{
7 Un férreo partidario de esta postura es Ernest J. Weinrib. Véase WeINRIB (2012a).

${ }^{8}$ WeINRIB (2012b), p. 10.

${ }_{9}$ Véase en general Goldberg y Zipursky (2010).

10 Sin perjuicio de que sería más correcto hablar de indemnización punitiva de perjuicios, adopto aquí la denominación de 'daños punitivos' por su uso más frecuente en la literatura.

11 Domínguez (1998), p. 49.

12 El carácter punitivo de estas cláusulas es la razón por la cual para el sistema inglés no son válidas aquellas cláusulas que penalizan el incumplimiento contractual. CARTWRIGHT (2013), pp. 215 y 288.
} 
podemos citar a Cristián Banfi del Río, quien recientemente ha sostenido que la responsabilidad civil no solo tiene un fin correctivo o compensatorio, sino que también es "un instrumento que atiende un fin retributivo en la medida que la indemnización encierra todos los daños que proceden directa y necesariamente del hecho ilícito doloso o gravemente descuidado". ${ }^{13}$

Sin perjuicio de lo anterior, el principio de justicia correctiva sigue siendo atractivo como justificación normativa del derecho privado. Como señala John Gardner, las consideraciones de justicia correctiva son necesarias (aunque no siempre suficientes) para articular cualquier explicación sobre la responsabilidad extracontractual. ${ }^{14}$ ¿Podemos, en consecuencia, vincular la restitución de ganancias obtenidas como consecuencia de la comisión de un ilícito civil o de un incumplimiento contractual con la concepción de justicia correctiva? En principio ello es posible. En su concepción aristotélica, la justicia correctiva persigue remediar o corregir las desigualdades que se producen entre las partes involucradas tanto en los tratos mutuos voluntarios como involuntarios, suponiendo la existencia de una situación de igualdad previa a la interacción entre las partes. ${ }^{15}$ En este sentido, quien obtiene un beneficio cometiendo un ilícito civil o un incumplimiento contractual ha perturbado la situación de igualdad preexistente entre las partes, toda vez que el beneficiado aumentó su patrimonio a expensas del otro.

Desde luego, es crucial en materia de enriquecimiento injustificado determinar si la ganancia o beneficio obtenido por el sujeto es jurídicamente justificable o no. ${ }^{16}$ Por ejemplo, es evidente que no todo individuo que obtiene un beneficio a expensas de la actividad de otro está obligado a restituir dicho beneficio. Como señala Peñailillo Arévalo, "[d]e lo que se trata es de exigir a todo enriquecimiento (...) una causa jurídicamente justificante, que en Derecho sea aceptable".$^{17}$ La justificación puede residir, como sostiene acertadamente este autor, en determinados actos jurídicos que permiten a los sujetos intervinientes enriquecerse, incluso a expensas del otro. Así, v. gr., el sistema jurídico chileno tolera que en un contrato de compraventa las

\footnotetext{
13 BANFI (2012), p. 6.

${ }^{14}$ Gardner (2011), pp. 5 y 6. A una similar conclusión llega, entre nosotros, Enrique Barros Bourie: "Ia justicia correctiva establece una condición que debe satisfacer toda decisión en materia de responsabilidad". BARROS (2006), p. 35.

15 ARISTÓteles (2008), Libro V.

${ }^{16}$ Por ello es que hemos preferido referirnos aquí al 'enriquecimiento injustificado' y no al 'enriquecimiento sin causa', aunque sea este último término el que se menciona con mayor frecuencia en la doctrina chilena.

17 Peñallillo (1996), p. 18.
} 
prestaciones no sean matemáticamente equivalentes, estableciendo correctivos solo para aquellos casos en los cuales hay una desproporción significativa (y solo para la compraventa de bienes inmuebles). Asimismo, el sistema jurídico tolera habitualmente enriquecimientos a expensas de otro. Por ejemplo, supongamos $M D$, un restaurante de comida rápida que se beneficia en virtud de que su competidor (BG) se retira del mercado. A menos que BG se haya retirado del mercado por efecto de una conducta ilícita de MD (como un acto de competencia desleal o una infracción al derecho de marcas), el sistema jurídico no le otorga a BG una acción para restituir las ganancias que MD ha obtenido como consecuencia del retiro de BG. De lo anterior se desprende que la justicia correctiva no provee de criterios para determinar cuándo el derecho debe intervenir efectuando la corrección que corresponda. ${ }^{18}$ Lo mismo ocurre en la responsabilidad extracontractual: Si MD decide abrir un local al frente de un local de propiedad de BG, provocando pérdidas para BG producto de una baja en sus ventas, el sistema jurídico prima facie no le otorga acción alguna para recuperar sus pérdidas. Ello incluso a pesar de que hay un vínculo de causalidad, que BG ha sufrido un daño, y que MD instaló su local con la expresa intención de provocar el daño a BG. La razón por la cual aquí no hay acción no reside en la justicia correctiva; es el sistema jurídico el que determina qué conductas y qué daños son objeto de protección.

\subsection{Las pérdidas y ganancias de la justicia correctiva}

Como vimos en la sección anterior, la justicia correctiva establece la operación mediante la cual el sistema jurídico corrige aquellas desigualdades que se producen como consecuencia de determinados hechos que el ordenamiento jurídico califica como ilícitos. De acuerdo a Aristóteles, las desigualdades que deben ser corregidas se originan como consecuencia de la existencia de una 'ganancia' por parte de quien comete la acción ilícita, y una 'pérdida' correlativa por parte de quien la sufre. ${ }^{19}$ Este requisito de equivalencia entre ganancias y pérdidas es problemático para el derecho privado. En muchas hipótesis de responsabilidad extracontractual, especialmente en aquellas que tienen que ver con descuidos momentáneos (por ejemplo, en accidentes automovilísticos), sería difícil estimar que el agente del daño ha obtenido alguna ganancia producto del accidente. En el contexto del enriquecimiento injustificado, al menos en

${ }^{18}$ Como señala John Finnis, la justicia correctiva deja intacto "un amplio rango de problemas", porque depende "de alguna determinación previa de qué ha de considerarse como crimen, agravio, acuerdo vinculante, etc.". FINNIS (2000), p. 207.

19 Aristóteles (2008): Libro V, 1132b. 
su vertiente moderna, surge el mismo problema a la inversa: nos encontramos ante la presencia de una ganancia sin una pérdida correlativa. ${ }^{20}$

Hay diversas formas de solucionar este problema. Para algunos, las nociones de 'ganancia' y 'pérdida' no son más que metáforas utilizadas por Aristóteles para capturar este fenómeno. ${ }^{21}$ Para otros, estos conceptos tienen un carácter normativo, por lo cual hay correlatividad en la medida en que haya una violación de un derecho de la víctima que provoca que esta tenga menos de lo que debiera tener y el otro tenga más de lo que debiera tener, conforme a las normas que regulan la interacción. ${ }^{22}$ Particularmente interesante para la discusión del enriquecimiento injustificado resulta la solución adoptada por James Gordley desde la perspectiva de la tradición aristotélica tomista. Siguiendo a Tomás de Aquino, Gordley sostiene que toda persona que agrede o agravia a otra recibe una ganancia "en tanto satisface sus deseos", lo que no necesariamente se traduce en un aumento del patrimonio. En consecuencia, para Gordley el concepto de justicia correctiva de Aristóteles corrige igualmente una situación de igualdad preexistente entre las partes, aun cuando quien causó el daño no obtuvo un beneficio económico. La razón de esto es que el autor del daño, al decidir dañar voluntariamente a su víctima, ha optado por utilizar los recursos de esta última para sus propios fines. ${ }^{23}$ Bajo esta concepción, puede sostenerse que el autor del daño satisface sus deseos a expensas de la víctima, de la misma forma que quien se enriquece injustificadamente obtiene un beneficio a expensas de otro. Nos encontramos en consecuencia con un sólido fundamento de justicia correctiva para sostener la acción de enriquecimiento injustificado, fundamento que establece la conexión de correlatividad normativa entre el enriquecido y quien interpone la acción. Precisamente, para Weinrib esta justificación es necesaria porque, de lo contrario, el sistema jurídico carece de justificación para transferir las ganancias al patrimonio del demandante y no a otra persona (o al Estado). ${ }^{24}$

Sin perjuicio de la fuerza que tiene dicha justificación, también hay buenas razones para mirar con sospecha al principio de justicia correctiva en este contexto,

\footnotetext{
${ }^{20}$ En la doctrina clásica del enriquecimiento injustificado no se presenta este problema, toda vez que establece como uno de sus requisitos la existencia de un 'empobrecimiento' correlativo al enriquecimiento. Peñallillo (1996), pp. 14-7.

21 WRIGHT (1992), p. 694.

22 WeINRIB (2012a), p. 115. Para Weinrib, el hecho que el sistema jurídico acoja, por medio del enriquecimiento injustificado, la restitución de ganancias materiales sin la existencia de pérdidas materiales correlativas confirma su tesis, según la cual en la justicia correctiva se trata de ganancias y pérdidas normativas, no materiales. WeINRIB (2012a), p. 117.

23 Gordley (2006), p. 183.

${ }^{24}$ WeInRIB, (2012b), p. 118.
} 
al igual que en el caso de la responsabilidad extracontractual. En primer lugar, en muchos casos resulta algo artificioso sostener que en toda ganancia injustificada obtenida a expensas de otro hay una pérdida correlativa. ${ }^{25}$ En el ejemplo del caballo Rocinante planteado más arriba en la introducción, en el cual Pedro utiliza sin autorización el caballo de Juan para participar en una carrera, difícil sería sostener que hay una pérdida para Juan si Pedro devuelve a Rocinante el mismo día sin causarle daño alguno (e incluso sin que Juan se percate de ello). Es más, podría sostenerse que Pedro entregó el caballo en mejor forma. ¿En qué sentido podría argumentarse que hay una pérdida para Juan? El fundamento de una acción restitutoria en este caso radicaría en el enriquecimiento de Pedro a expensas de los recursos de Juan (Rocinante). Sin embargo, la exigencia de justicia correctiva no se satisface, ya que la acción de Pedro no ha causado empobrecimiento alguno para Juan. Como ya se mencionó anteriormente, autores como Weinrib rescatan la justicia correctiva para este tipo de casos, sosteniendo que hay aquí una pérdida normativa que es correlativa a la ganancia de Pedro, por cuanto este último interfirió ilícitamente con el derecho de propiedad de Juan. Sin embargo, al menos intuitivamente, no parece haber pérdida alguna para Juan; solo forzando el concepto de pérdida podríamos llegar a un resultado distinto.

En segundo lugar, otra razón para mirar con sospecha la justicia correctiva como fundamento exclusivo de la acción para restituir ganancias lo constituyen aquellos casos en los cuales la acción restitutoria persigue un fin ajeno a la justicia correctiva, que consiste en desincentivar la comisión de ilícitos. Se trata de lo que James Edelman denomina como disgorgement damages, que se distinguen tanto de los restitutionary damages (restitución propiamente tal) como de los compensatory damages (indemnización compensatoria). ${ }^{26}$ La interacción entre estos mecanismos es compleja, y la discusión en torno a sus líneas divisorias será desarrollada a lo largo del presente trabajo. Por cierto, la distinción de Edelman entre la restitución de ganancias y la restitución propiamente tal no es unánime en la doctrina. ${ }^{27}$ No obstante, sin necesariamente comprometerse

\footnotetext{
${ }_{25} \mathrm{Al}$ igual que en responsabilidad extracontractual, donde también resulta discutible, como ya mencionamos, la existencia de ganancias en casos de descuidos momentáneos, o descuidos leves que causan daños desproporcionadamente graves.

${ }^{26}$ Edelman (2002)

27 Por ejemplo, para Andrew Burrows aunque resulta atractivo en principio distinguir entre las transferencias de valor y la restitución de ganancias, no es del todo claro que constituyan categorías separadas de restitución. Más bien, se trataría de dos funciones separables de la restitución. Burrows (2007), p. 634. En el mismo sentido, Katty Barnett sostiene que "a pesar de que la distinción de Edelman entre disgorgement damages y restitutionary damages es atractiva, debe ser rechazada. La razón principal para ello es que en muchos casos resulta muy difícil identificar la transferencia de valor entre el demandante y el demandado". BARNETT (2012), p. 151.
} 
con esta distinción en términos conceptuales, podemos apreciar las distintas funciones que desempeña cada una de ellas.

En este sentido, podemos señalar que en la acción restitutoria propiamente tal se persigue la transferencia del valor equivalente a la ganancia obtenida por el demandado a expensas del demandante. Ejemplo paradigmático de una acción de esta naturaleza entre nosotros es el pago de lo no debido (artículos 2295 a 2303 del Código Civil), donde el demandante solicita la transferencia del monto exacto de lo que el demandado se enriqueció a sus expensas (el valor exacto de lo que indebidamente se pagó). En estos casos claramente hay correlatividad entre el enriquecimiento del demandado, por una parte, y el empobrecimiento del demandante, por la otra, situación que amerita ser corregida en virtud de la justicia correctiva. Sin embargo, Edelman sostiene que los sistemas jurídicos también contemplan otros mecanismos que no persiguen rectificar transferencias de valor, sino prevenir la comisión de ilícitos, situaciones que con frecuencia se vinculan a acciones fraudulentas o dolosas por parte de quien se ha enriquecido. En estos casos, la acción restitutoria materializa con la restitución o devolución de las ganancias o el provecho obtenido por el demandado como consecuencia de la comisión del ilícito. Para Edelman, estas acciones se sustentan en la disuasión o prevención y no en la justicia correctiva. ${ }^{28}$ Para otros, el fundamento de estos mecanismos reside tanto en consideraciones disuasivas (es decir, en prevenir que ocurran actos ilícitos en el futuro) como retributivas (esto es, como una respuesta del sistema jurídico frente a un acto fraudulento). ${ }^{29}$

Acciones de esta naturaleza no son ajenas a nuestro ordenamiento jurídico. Así, v. gr., el artículo 1558 del Código Civil establece que quien incumple dolosamente un contrato es responsable incluso de aquellos perjuicios que no podrían haber sido previstos al momento de celebrar el contrato, en la medida que sean "una consecuencia inmediata o directa de no haberse cumplido la obligación". La justificación de esta norma no puede radicar en el principio de justicia correctiva, puesto que tanto el incumplimiento culpable como el incumplimiento doloso de un contrato producen la misma situación de desigualdad entre las partes; ambas situaciones ameritan el mismo tratamiento desde la perspectiva de la justicia correctiva. La norma puede entenderse desde una perspectiva disuasiva: ${ }^{30}$ quien actúa dolosamente se arriesga a verse obligado a indemnizar incluso daños imprevistos o imprevisibles.

\footnotetext{
${ }^{28}$ Edelman (2002), p. 83. Intentos por conciliar estos mecanismos indemnizatorios con la justicia correctiva pueden encontrarse en BENSON (2004); BOtTRELL (2010).

29 "Las justificaciones morales detrás de los disgorgement damages son la disuasión y la retribución". BARNETT (2012), p. 46.

${ }^{30}$ Sin perjuicio de que también pueda interpretarse que el fundamento de la norma es punitivo.
} 
Asimismo, este fundamento disuasivo puede encontrarse en la acción del provecho por dolo ajeno de los artículos 1458 y 2316 del Código Civil. Más adelante en este trabajo (sección quinta) se argumentará que la naturaleza jurídica de esta acción es restitutoria, toda vez que no requiere la existencia de un daño para ser procedente; solo se requiere la concurrencia de una conducta fraudulenta y un beneficio obtenido por una tercera persona, distinta a quien cometió el acto fraudulento. Por ahora, solo cabe señalar aquí que si la naturaleza jurídica de la acción es restitutoria, como se argumentará más adelante, la acción del provecho por dolo ajeno constituiría una hipótesis de restitución de ganancias que tiene un fundamento principalmente preventivo o disuasivo. ${ }^{31}$ En este sentido, la norma perseguiría prevenir la comisión de actos dolosos, estableciendo la restitución de ganancias incluso respecto de un tercero inocente. Por ello es que, según se argumentará más adelante en la sección 5, esta acción no requiere la existencia de un empobrecimiento o daño correlativo para la víctima del dolo.

En conclusión, si bien la justicia correctiva puede justificar satisfactoriamente algunas hipótesis restitutorias, la exigencia de correlatividad entre pérdidas y ganancias es problemática en otras hipótesis restitutorias. Al igual que lo que ocurre en algunos casos de responsabilidad extracontractual, en donde es difícil determinar la existencia de una ganancia para quien causa el daño, en muchas hipótesis de enriquecimiento injustificado es difícil determinar la existencia de una pérdida para el demandante. Como observa Peter Birks, los sistemas jurídicos ofrecen distintas soluciones a este problema, exigiendo algunos la existencia de una pérdida correlativa para entablar la acción restitutoria, y otros prescindiendo de ella. ${ }^{32}$ Doctrinariamente, la concepción normativa de las ganancias y pérdidas en la justicia correctiva pareciera ser la vía más aconsejable para resolver este problema. Sin embargo, una dificultad adicional para la justicia correctiva lo constituyen otras hipótesis de restitución, en especial aquellas en las cuales se persigue la restitución de ganancias obtenidas como consecuencia de una conducta fraudulenta. En estos casos, el fundamento es principalmente de carácter disuasivo. Dicho esto, cabe cuestionarse cuál es el fundamento (si es que lo hay) de una acción restitutoria general para recobrar las ganancias obtenidas

\footnotetext{
31 No resulta del todo descartable la posibilidad de justificar la acción sobre la base de la justicia correctiva, en razón de que la norma permite a la víctima del ilícito que se le restituyan las ganancias que un tercero obtuvo a expensas de ella. Sin embargo, si el fundamento es la justicia correctiva, ¿por qué la hipótesis se limita al dolo? ¿No debiera establecerse una acción para cualquier caso en el cual un tercero se beneficia de un acto negligente? Solo mediante el uso de razones preventivas o retributivas es posible restringir la hipótesis al dolo. No obstante, me parece que en este caso las consideraciones disuasivas son preponderantes.

32 BIRKS (2003), p. 65.
} 
como consecuencia de un ilícito civil o de un incumplimiento contractual. ¿Es posible justificar estas acciones con base en la justicia correctiva, o se trata de aquellas situaciones que no pueden ser explicadas por dicho principio?

\section{Restitución de ganancias obtenidas como consecuencia de un ilícito civil}

Teniendo presente el fundamento disuasivo de las acciones de restitución de ganancias ilícitas, comenzaremos el estudio específico de estas acciones en el ámbito de la responsabilidad extracontractual, esto es, los mecanismos que el sistema jurídico otorga a la víctima de un ilícito para que se le restituyan las ganancias obtenidas por el autor del ilícito al momento de su comisión. Para ello se estudiarán los mecanismos que los sistemas del common law establecen para tal efecto, y analizar la posibilidad de incorporar estos mecanismos al ordenamiento jurídico chileno.

Los casos paradigmáticos de restitución de ganancias en este ámbito lo constituyen aquellos en los cuales se ha visto afectado un derecho de propiedad del demandante, ${ }^{33}$ como ocurre en el caso de nuestro ejemplo del caballo Rocinante. Para Weinrib, estas situaciones son cubiertas satisfactoriamente por la justicia correctiva, en virtud de que el derecho de propiedad le otorga al propietario el atributo exclusivo para usar y gozar del bien objeto del derecho. ${ }^{34}$ De lo anterior se sigue que si otra persona goza del bien sin la autorización del dueño, es procedente que restituya los beneficios que con dicho goce ha obtenido. El requisito de correlatividad se cumpliría en este caso en razón de que el derecho de propiedad le otorga al propietario el atributo exclusivo de gozar de la cosa, que es correlativo al deber que tienen las demás personas de abstenerse de gozar de la misma. En consecuencia, "la concreción de una ganancia no autorizada constituye una injusticia" entre el propietario y el autor del ilícito. ${ }^{35}$

En nuestro ordenamiento jurídico podemos encontrar una hipótesis de esta naturaleza en el artículo 108 letra b) de la Ley № 19.039, de 1991, en el cual se permite al demandante solicitar que la indemnización de perjuicios se determine de acuerdo a las "utilidades que haya obtenido el infractor como consecuencia de la infracción". No obstante que la norma utilice la expresión "indemnización de perjuicios", se trata más propiamente de una

\footnotetext{
${ }^{33}$ La razón por la cual ello es así reside en que las demás hipótesis de ilícitos civiles (cubiertas en nuestro ordenamiento jurídico por el sistema de responsabilidad extracontractual) implican necesariamente la existencia de un daño para la víctima. Por las razones que se explican más abajo en la sección vı del presente trabajo, la acción restitutoria de ganancias ilícitas que aquí se defiende es incompatible con una acción indemnizatoria por el mismo hecho.

34 WeINRIB (2012b), p. 125.

35 WeINRIB (2012b), p. 126.
} 
hipótesis de restitución de ganancias, puesto que la determinación del monto a pagar por el demandado no tiene relación alguna con un daño causado al demandante. Así también lo estimó recientemente una sentencia del Tribunal Constitucional. ${ }^{36}$

Otro ejemplo en nuestro ordenamiento puede encontrarse en el contexto de las prestaciones mutuas a que da lugar la acción reivindicatoria. El artículo 906 del Código Civil establece que incluso el poseedor de buena fe es responsable de los deterioros que por su hecho o culpa ha sufrido la cosa objeto de la reivindicatoria, "en cuanto se hubiere aprovechado de ellos". En este sentido, la norma obliga incluso a quien se encuentra de buena fe en posesión de la cosa reivindicada a restituir los beneficios que hubiere obtenido con el uso de la propiedad ajena. Por otra parte, el poseedor de mala fe es obligado a restituir los frutos naturales y civiles de la cosa reivindicada (artículo 907 del Código Civil). Ambas normas establecen claras hipótesis de restitución de ganancias ilícitas.

Para nuestro ordenamiento jurídico este tipo de situaciones no configuran necesariamente hipótesis de responsabilidad extracontractual, a menos que el demandante haya sufrido un daño como consecuencia del hecho que generó las ganancias. En este sentido, para nosotros estas serían hipótesis de enriquecimiento injustificado, y así se ha sostenido por la doctrina. ${ }^{37} \mathrm{Sin}$ embargo, la distinción teórica del common law entre aquellas hipótesis de enriquecimiento injustificado que se originan como consecuencia de un ilícito civil y aquellas que no tienen como origen un ilícito es aplicable a nuestro ordenamiento, aun cuando el tratamiento sistemático de la responsabilidad extracontractual sea distinto. Como ya hemos señalado, en los sistemas de common law el daño no siempre es requisito necesario para entablar una acción de responsabilidad extracontractual. Tal es el caso, por ejemplo, de la hipótesis del trespass to land, en la cual la sola afectación del derecho de propiedad le otorga al propietario el derecho a interponer una acción de responsabilidad civil en contra de quien cometió el ilícito. Podría sostenerse que en este tipo de casos el sistema jurídico supone la existencia de un daño

${ }^{36}$ El Tribunal señaló que "mirado en su conjunto, el artículo 108 contempla una hipótesis de lucro cesante (la indicada en el literal ' a' ...), y dos hipótesis amplias de enriquecimiento ilícito (la expresada en el literal ' $\mathrm{C}$ ' ...) y la impugnada en autos como pretensión de enriquecimiento injusto, a saber, 'las utilidades que haya obtenido el infractor como consecuencia de la infracción' (artículo 108, literal ' $\left.b^{\prime}\right)^{\prime}$. Tribunal Constitucional, Rol No 2.437, 14 de enero de 2014, considerando vigésimo octavo. Desafortunadamente, el Tribunal concluye con posterioridad (a mi juicio, erróneamente) que la norma es inconstitucional, por razones que no cabe discutir aquí.

${ }_{37}$ Así por ejemplo, Peñailillo ejemplifica una situación de enriquecimiento injustificado con una hipótesis que para el common law constituiría una restitución por ilícito de propiedad. PeÑalııLo (1996), p. 15. 
al afectarse el derecho de propiedad, aunque se estime que dicho daño es solo 'nominal' al ser avaluado en concreto. ${ }^{38}$

Sea esto así o no, y aunque en nuestro ordenamiento jurídico estas situaciones no formen parte del sistema de responsabilidad extracontractual (en tanto no exista daño), igualmente se puede apreciar la diferencia entre tales casos y aquellas hipótesis de enriquecimiento injustificado en las cuales no hay un elemento de ilicitud involucrado. Así, v. gr., en el pago de lo no debido no se requiere la concurrencia de un elemento normativo de ilicitud para configurar la acción restitutoria; solo es requisito que se haya efectuado un pago, y que dicho pago se haya efectuado por un error (incluso de derecho). En cambio, en la hipótesis recién enunciada de obtención de ganancias como consecuencia de una infracción a un derecho de propiedad, es un requisito indispensable que previamente se haya afectado un derecho de propiedad. Lo mismo para el caso de la norma del artículo 108 letra b) de la Ley No 19.039, de 1991, la cual supone la infracción al derecho de propiedad industrial. Por esto es que en términos generales puede sostenerse que el pago de lo no debido es el caso paradigmático de enriquecimiento injustificado, puesto que solo toma en cuenta la transferencia injustificada de valor entre el demandante y demandado, sin suponer que el demandado haya actuado ilícitamente como requisito previo. ${ }^{39}$

En el pago de lo no debido simplemente hay una transferencia de valor realizada por el demandante al demandado que debe ser corregida en virtud de la justicia correctiva, como advertimos en la sección anterior. Sin embargo, en las hipótesis que aquí nos interesan no hay una transferencia de valor del

\footnotetext{
${ }^{38}$ Una hipótesis interesante que solo puedo enunciar aquí es la interpretación que Eric Descheemaeker plantea del concepto de delito y cuasidelito adoptado por Pothier en su Tratado de las Obligaciones. Pothier en el parágrafo 116 define al delito como el "hecho por el cual una persona, por dolo o malignidad, injuria [tort] o causa daño a otra", y al cuasi-delito como "el hecho por el cual una persona, sin malignidad, sino por una imprudencia que no es excusable, injuria [tort] o causa algún daño a otro". POthier (2003), p. 73. La noción de injuria en este contexto aludiría a la noción romana de actio iniuriarum, que no se restringe exclusivamente a la difamación, sino tiene un sentido más amplio asociado en general a la violación de un derecho de la personalidad de la víctima (contumelia). Zimmermann (1990), p. 1059. Descheemaeker concluye entonces que "para Pothier, el daño no es un elemento esencial del delito o cuasidelito", porque incluiría también la posibilidad de la injuria entendida como la violación de un derecho. Descheemaeker (2009), p. 114. Andrés Bello siguió al Código francés al incluir la noción de daño para la definición del cuasidelito en los artículos 2314 y 2329 del Código Civil. Sin embargo, Bello también siguió a Pothier en otras disposiciones del Código. Así, el Código menciona el concepto de injuria al definir el dolo (artículo 44) y al enumerar las fuentes de las obligaciones (artículo 1437). Todo ello permitiría concluir que Bello no descartó la posibilidad de configurar un ilícito de responsabilidad extracontractual como consecuencia de la violación de un derecho de la víctima, aunque con ello no se cause un daño.

${ }^{39}$ Incluso para Birks "el enriquecimiento injustificado es el derecho que cubre todos los eventos materialmente idénticos al pago de lo no debido". BiRks (2003), p. 3.
} 
demandante al demandado; lo que fundamenta la acción es el uso inapropiado (o no autorizado) de la propiedad del demandante. El caso estadounidense Edwards v Lee's Administrator (1936) ${ }^{40}$ (en adelante Edwards) es un claro ejemplo de este tipo de hipótesis. El demandado, Edwards, descubrió una caverna de roca de cristal en el subsuelo de su propiedad. Edwards explotó esta caverna como atracción turística con el nombre de "Great Onyx Cave". Sin embargo, una sección de esta caverna pertenecía al subsuelo de una propiedad colindante, cuyo dueño era el demandante, Lee. Los herederos de Lee entablaron una acción en contra de Edwards, solicitando que este cese de utilizar el subsuelo perteneciente a su propiedad, y adicionalmente que Edwards restituya las ganancias obtenidas como consecuencia del ilícito civil (el ilícito de trespass). La Corte de Apelaciones de Kentucky resolvió otorgarle a los demandantes la restitución de un tercio de las ganancias obtenidas por Edwards mediante la explotación turística de las cavernas, proporción que se calculó basada en la porción de terreno que correspondía a Lee de la caverna completa. De inmediato puede apreciarse una diferencia conceptual entre esta situación y una hipótesis de pago de lo no debido. En Edwards la ilicitud está determinada por la violación al derecho de propiedad de Lee. No obstante que nuestro sistema jurídico, a diferencia del common law, no otorgaría una acción de responsabilidad extracontractual por la sola violación al derecho de propiedad, la existencia de un derecho de propiedad a favor de Lee es lo que determina su derecho a ser el beneficiario exclusivo de los frutos que produzca su propiedad.

¿Podría sostenerse en nuestro ordenamiento jurídico que Lee tendría un derecho de dominio sobre el subsuelo de su predio? En el caso se determinó que el derecho de dominio se extendía al subsuelo sobre la base de la antigua máxima "por arriba hasta el cielo, por abajo hasta el infierno". ${ }^{41}$ Sin perjuicio de que nuestro Código Civil no contiene una norma expresa sobre la materia, Peñailillo Arévalo sostiene que una postura más razonable al respecto se funda en la noción de utilidad, extendiendo el propietario su dominio al subsuelo "en la medida en que el interés y provecho del ejercicio de su dominio lo justifica; y quedando siempre a salvo las limitaciones en el interés común". ${ }^{42}$ De tal manera que nuestro sistema jurídico también le reconocería un derecho de dominio a Lee sobre el subsuelo. Sería procedente entonces acoger una acción restitutoria utilizando el mismo razonamiento de la Corte de Apelaciones de Kentucky. Según la Corte, no hay en este caso una "pérdida tangible que no sea

${ }^{40}$ Court of Appeals of Kentucky, 96 S.W. 2d 1028 (1936), 5 de junio de 1936.

${ }^{41}$ Edwards v Lee's Administrator (1936), p. 1029.

42 Peñailillo (2010), p. 66. 
la violación de un derecho", por lo cual el único mecanismo que dispone el derecho para remediar esta situación es la restitución de ganancias. ${ }^{43}$

No obstante lo anterior, alguien podría sostener que en este caso sí hay una especie de pérdida para el demandante en términos de lucro cesante, esto es, lo que se dejó de percibir por la explotación turística de la porción de la caverna que correspondía al predio de Lee. Esta solución podría ser aplicable a hipótesis similares, como la de nuestro ejemplo del caballo Rocinante, en las cuales el demandante podría optar por interponer una acción de responsabilidad extracontractual. Sin embargo, esta interpretación no se sostiene en el caso de Edwards, toda vez que no parece que el demandante tuviera intención alguna de explotar la porción de caverna que correspondía a su predio. A mayor abundamiento, cabe tener presente que la única forma de acceder a la caverna era a través de la propiedad del demandado, con lo cual la posibilidad que tenía el demandante para explotar por sí solo la caverna era restringida (sujeta a obtener una autorización por parte de Edwards para dar acceso a la caverna).

Por otra parte, como ya anunciamos anteriormente, es posible también sostener que la violación del derecho de propiedad constituye en sí una pérdida, la cual sería correlativa a las ganancias obtenidas por el demandante como consecuencia de dicha violación al derecho de propiedad. Weinrib llega a esta conclusión sobre la base de una concepción kantiana del derecho de propiedad, según la cual el derecho le otorga al propietario el derecho exclusivo a obtener los frutos de dicha propiedad. Arthur Ripstein llega a una conclusión similar, sosteniendo que se trata de una hipótesis en que se afecta la libertad del propietario. Ello se debe a que para Ripstein, los propietarios tienen derecho a usar sus bienes en la forma que estimen conveniente para alcanzar los fines que hayan decidido perseguir. De tal manera que la única forma de remediar el uso no autorizado de la propiedad es tratar dicho uso como si hubiera sido empleado para el solo beneficio del propietario, procediendo en consecuencia la restitución de ganancias. ${ }^{44}$ Ambas posturas derivan de una concepción kantiana del derecho de propiedad, y recogen la fuerza atractiva del principio de justicia correctiva con la correlatividad de ganancias y pérdidas normativas.

Sin embargo, el principio de justicia correctiva por sí solo no se compromete con alguna concepción particular acerca del derecho de propiedad, así como tampoco determina cuáles interacciones merecen ser corregidas y cuáles no. ${ }^{45}$

\footnotetext{
43 Edwards v Lee's Administrator (1936), p. 1032.

44 RIPSTEIN (2004), p. 24.

${ }^{45}$ Como señala John Finnis, la justicia correctiva deja intacto "un amplio rango de problemas", porque depende "de alguna determinación previa de qué ha de considerarse como crimen, agravio, acuerdo vinculante, etc.". FINNIS (2000), p. 207.
} 
En este sentido, resulta interesante analizar cómo en este tipo de casos se reflejan las concepciones sustantivas acerca del derecho de propiedad que pueden ser puestas en práctica mediante el mecanismo de la justicia correctiva. Gordley, por ejemplo, parte de la base de un concepto aristotélico del derecho de propiedad, en virtud del cual la propiedad privada es necesaria para solucionar los problemas derivados de la propiedad común, otorgando incentivos para aprovechar estos bienes y cuidarlos. ${ }^{46}$ De esta concepción funcional de la propiedad privada se sigue que el derecho exclusivo del propietario a aprovecharse del bien que le pertenece debe reconocer límites. ${ }^{47}$ Así, v. gr., normalmente se menciona que quien se encuentra en una necesidad urgente (en un estado de necesidad) puede legítimamente apropiarse de un bien ajeno. En el mismo sentido, Gordley apela a los límites del derecho de dominio que mencionamos anteriormente para argumentar que la función del derecho de propiedad debe ser tomada en cuenta en este tipo de casos. Por cierto, sería un despropósito que a un propietario se le otorgara una acción restitutoria por las ganancias obtenidas por aviones que han sobrevolado el espacio aéreo que se encuentra sobre su propiedad.

Para Gordley entonces, este tipo de situaciones deben ser analizadas teniendo en cuenta la función que cumple el derecho de propiedad, el cual otorga a su titular el derecho a que los demás no interfieran con su uso de la propiedad. Sin embargo, en una concepción funcional de la propiedad privada, la protección solo se extiende a aquellas interferencias que afectan la privacidad del propietario o que perturban el desarrollo de sus actividades. Por ello, argumenta Gordley, el propietario no podría "quejarse por las ondas de radio o televisión que ingresen a su propiedad, a menos que dichas ondas interfieran con su propia recepción" de radio o televisión..$^{48}$ En consecuencia, para Gordley sería discutible otorgarle a Juan una acción restitutoria en contra de Pedro por el uso no autorizado de Rocinante, así como también resultaría discutible la decisión adoptada en el caso Edwards.

¿Nos vemos forzados, entonces, a concluir que en aquellos casos en los cuales el uso no autorizado de propiedad ajena no afecta la privacidad del propietario o perturba el desarrollo de sus actividades el propietario no tiene acción alguna? Gordley sostiene que se trata de problemas complejos, en los cuales por una parte no debiera permitirse que los individuos utilicen bienes

\footnotetext{
46 Gordely (2006), p. 446.

47 También puede llegarse a esta conclusión en virtud de la justificación que elabora Locke de la propiedad privada basada en el trabajo, que reconoce un conjunto de límites (dejar suficientes bienes de igual calidad para el resto, apropiarse solo de aquellas cosas que pueden aprovecharse antes de que se echen a perder, y apropiarse solo de la cantidad que pueda procurarse un hombre por su propio trabajo). LOCKE (1997).

${ }^{48}$ Gordley (2006), p. 448.
} 
ajenos sin solicitar la correspondiente autorización previa del propietario. Pero por otra parte, tampoco resulta conveniente (desde el punto de vista funcional del derecho de propiedad) otorgarle al propietario la prerrogativa ilimitada de negarse a que otros utilicen su propiedad para gozar de sus frutos. A este respecto, hay que señalar que la postura de Gordley no parece consistente con su concepción de ganancias y pérdidas correlativas de la justicia correctiva que fue enunciada en la sección anterior. Si un individuo obtiene un beneficio utilizando recursos ajenos, esto es, a expensas de otro, la justicia correctiva demanda que dicho sujeto restituya ese beneficio al propietario del bien explotado. Las consideraciones funcionales no tienen lugar en este examen que se limita a determinar si ha existido o no un enriquecimiento a expensas de otro. La justificación funcional solo puede tener lugar en un segundo examen, que consiste en determinar si el enriquecimiento en cuestión es justificado o no. En este examen, entran en juego las consideraciones funcionales de la propiedad que plantea Gordley. En virtud de ello es que el derecho de dominio no se extiende en el plano vertical ilimitadamente; deben reconocerse algunos límites basados en la función social de la propiedad.

Si bien es cierto que el sistema jurídico no debiera otorgarle al propietario la prerrogativa de negarse o cobrar un precio excesivo al demandado para darle acceso a los pasajes subterráneos de su predio, una acción restitutoria no le impondría al demandado un precio excesivo o la imposibilidad de utilizar los pasajes; solo le impondría la obligación de pagar una renta, a precio de mercado, que equivale al valor de lo que habría pagado el demandado para obtener la autorización del propietario. Ello parece ser la solución más equitativa en este caso, que permite conciliar, por una parte, los intereses del propietario en gozar exclusivamente del bien y, por otra, los intereses sociales involucrados en el uso de la propiedad para beneficio común. Soluciones de esta naturaleza no son ajenas a nuestro ordenamiento jurídico. Así, v. gr., el artículo 626 del Código Civil resuelve la situación en la cual un sujeto encuentra un tesoro en terreno ajeno. El Código Civil claramente se inclina por proteger los intereses del propietario por sobre quien realiza el descubrimiento (que podría considerarse como representando los intereses sociales), puesto que este último tiene derecho a la mitad del valor del tesoro solo si el descubrimiento es fortuito o se ha buscado con autorización previa del dueño. En los demás casos, el tesoro pertenece exclusivamente al dueño del terreno. Puede discutirse si se trata o no de una solución equitativa; lo que no puede discutirse es que se trata de una solución para conciliar estos intereses del derecho de propiedad. ${ }^{49}$

${ }^{49}$ Véase también las reglas de accesiones continuas no naturales del Código Civil (artículos 657 y siguientes). 


\section{Restitución de ganancias obtenidas como consecuencia de un incum- plimiento contractual}

¿Podemos extender el razonamiento anterior referido a ilícitos extracontractuales a aquellos casos en los cuales se han obtenido ganancias como consecuencia de un incumplimiento contractual? Se trataría de situaciones no cubiertas por el estatuto de responsabilidad contractual, esto es, de aquellos casos en los cuales el incumplimiento contractual no ha provocado perjuicios para la parte diligente, o en aquellos casos en los cuales la parte incumplidora ha obtenido ganancias que superan los perjuicios ocasionados a la parte diligente. En nuestro ejemplo, ¿es posible para Cola-Cola entablar una acción restitutoria en contra de Carlos por la ganancia obtenida por este con la venta de la fórmula secreta, en virtud de que el incumplimiento contractual no ha generado daño alguno, o los daños son inferiores a la ganancia obtenida con la venta? Si concluimos en la sección anterior que es posible establecer la existencia de una acción restitutoria para recuperar las ganancias obtenidas como consecuencia de un uso no autorizado de propiedad ajena, ¿no debiéramos concluir lo mismo respecto de las ganancias obtenidas como consecuencia de un incumplimiento contractual?

Algunos han sostenido que el derecho le otorga a las partes una especie de derecho de dominio sobre los contratos. ${ }^{50}$ En otras palabras, en virtud de esta doctrina, las partes serían dueñas de sus contratos. Sin perjuicio de que intuitivamente esta idea puede ser atractiva, en muchos casos no resulta aplicable. Así, v. gr., en el caso de los contratos de trabajo difícilmente podríamos sostener que las partes son dueñas de los contratos..$^{51}$ En cualquier caso, dado que la restitución de ganancias debiera ser aplicable a la comisión de ilícitos, es razonable al menos preguntarse si también este mecanismo debiera estar disponible para los incumplimientos contractuales. En el caso inglés Wrotham Park Estates Ltd. v Parkside Homes Ltd. (1973) ${ }^{52}$ (en adelante Wrotham Park) se plantea esta analogía.

\subsection{Wrotham Park}

En Wrotham Park, Parkside construyó un conjunto de casas en un terreno colindante con el de los demandantes, violando una cláusula contractual,

\footnotetext{
50 Friedmann (1980), p. 515.
}

${ }^{51}$ El mismo Friedmann reconoce esta limitación. FriedmanN (1980), p. 520. También Weinrib critica esta postura desde su punto de vista teórico. Siguiendo a Kant, Weinrib sostiene que el demandante no adquirió un derecho de dominio sobre el objeto del contrato, sino que solo adquirió la promesa de que el demandado cumplirá su obligación. WeINRIB (2012b), p. 154.

52 Chancery Division [1974] 1 WLR 798, 19 de octubre de 1973. 
según la cual se requería la aprobación de planos previa de los demandantes para edificar en dicho terreno. En la sentencia, el juez Brightman reconoce que Parkside violó la cláusula contractual al construir el conjunto de casas sin la autorización previa de los demandantes. Sin embargo, la Corte se niega a ordenar la destrucción de las casas, ya que ello constituiría un "desperdicio imperdonable de tan requeridas viviendas" ${ }^{53}$ ¿Cómo podría, entonces, remediarse el incumplimiento contractual y al mismo tiempo evitar que más casas se construyan contraviniendo una cláusula contractual? Parkside y los demás demandados (los dueños de las casas construidas) argumentaron que los demandantes no sufrieron perjuicio alguno por la construcción de las casas; a lo sumo habrían sufrido un daño nominal o simbólico. Sin embargo, el denegar la orden de destruir las casas y otorgar solo una indemnización nominal de perjuicios sería un resultado claramente injusto, toda vez que ello permitiría a los demandados gozar de los frutos de su ilícito y dejaría a los demandantes sin compensación alguna.

Para el juez, se trata del mismo problema que se produce con la obtención de ganancias como consecuencia de un uso no autorizado de propiedad ajena. ${ }^{54}$ Siguiendo la lógica de estos casos, se determinó que el mecanismo para calcular el monto a pagar por los demandados debe ser equivalente a la "suma de dinero que los demandantes habría razonablemente exigido a Parkside como quid pro quo para relajar la aplicación de la cláusula"..$^{55}$ Lo interesante es que el juez sostiene que para calcular esta suma de dinero debemos suponer que los demandantes, reticentes a relajar la aplicación de la cláusula, le habrían preguntado primero a Parkside cuántas utilidades en total obtendrían con el desarrollo inmobiliario. Por lo tanto, el monto a pagar debe corresponder a un porcentaje de las utilidades obtenidas por Parkside, que ascendían a £50.000. Se estimó que un porcentaje razonable era de 5\%, con lo cual el monto a pagar se fijó en $£ 2.500$.

Determinar si el pago de esta suma de dinero es de naturaleza indemnizatoria o restitutoria ha generado un intenso debate en la doctrina inglesa. En principio pareciera tratarse de una indemnización de perjuicios, y es la interpretación que resulta más fiel al tenor literal del argumento del juez Brightman. El monto estaría indemnizando lo que el demandante dejó de obtener si se hubiere solicitado su autorización para modificar la cláusula del contrato. El mismo razonamiento puede emplearse para calificar de indemnizatorio el monto que el artículo 108

53 Wrotham Park Estates Ltd. v Parkside Homes Ltd. (1973), p. 811.

54 Wrotham Park Estates Ltd. v Parkside Homes Ltd. (1973), p. 812.

55 Wrotham Park Estates Ltd. v Parkside Homes Ltd. (1973), p. 815. 
letra c) de la Ley № 19.039, de 1991, permite solicitar al demandante. Señala la norma que el demandante puede solicitar "el precio que el infractor hubiera debido pagar al titular del derecho por el otorgamiento de una licencia, teniendo en cuenta el valor comercial del derecho infringido y las licencias contractuales que ya se hubieran concedido".

Sin embargo, ello supone que el demandante habría estado dispuesto a aceptar el pago de un precio por relajar la aplicación de la cláusula del contrato o el uso de la propiedad inscrita, lo cual no siempre se cumple. En el mismo caso Wrotham Park, el juez reconoce que todo indica que los demandantes no habrían aceptado relajar la aplicación de la cláusula, pero "para estos propósitos, debo asumir que ellos podrían haber sido inducidos a aceptarlo" ${ }^{\prime 56}$. Esta es la razón por la cual para Andrew Burrows calificar de indemnizatorio estos pagos resulta ficticio. Hay una ficción en cuanto a que supone que el demandante estaba dispuesto comprar el derecho del demandado, y a su vez supone hipotéticamente que el demandado habría estado dispuesto a vender su derecho y por el monto fijado por el tribunal. En muchos casos, estas suposiciones son manifiestamente falsas, como en Wrotham Park. En consecuencia, Burrows sostiene que resulta más realista calificar estos pagos como restitutorios. ${ }^{57}$ Edelman llega a la misma conclusión, sosteniendo que este tipo de pagos constituyen una hipótesis de restitución propiamente tal (restitutionary damages). ${ }^{58}$

Otros autores concluyen que se trata de un mecanismo sui generis, que no reviste el carácter de indemnizatorio ni restitutorio. En este sentido, Robert Stevens elabora la noción de indemnización 'sustitutiva' de perjuicios o 'daños sustitutivos' (substitutive damages), sosteniendo que estos pagos sustituyen el valor del derecho primario que ha sido infringido en el caso particular (el derecho a autorizar o no la construcción de las casas en Wrotham Park, o el derecho a autorizar o no el uso de la patente inscrita)..$^{59}$ Gordley también sostiene que estos pagos no son indemnizatorios ni restitutorios, sino que se trataría de una solución adoptada por la Corte para efectos de no imponerle al demandante una venta forzada de su derecho al demandado. Así, señala Gordley, la suma de dinero persigue incentivar que el demandado solicite la autorización previa

\footnotetext{
56 Wrotham Park Estates Ltd. v Parkside Homes Ltd. (1973), p. 815.

57 Burrows (2007), p. 636.

${ }^{58}$ Edelman (2002), p. 101.

59 Stevens (2007), p. 68. En una línea similar, Kit Barker recientemente ha sostenido que estos pagos tienen un carácter indemnizatorio, en el sentido de que compensan la pérdida que sufre el demandante por la violación de su derecho primario (su derecho a otorgar o no la autorización respectiva). Barker argumenta que se trata de una pérdida porque estos derechos tienen un valor económico. BARKER (2014), p. 27.
} 
del demandado, y no se limite a compensar al demandante los daños causados una vez que ha violado su derecho. ${ }^{60}$

¿Cuál es la naturaleza jurídica entonces del recién mencionado artículo 108 letra c) de la Ley № 19.039, de 1991? Nos inclinamos por la naturaleza jurídica restitutoria, ${ }^{61}$ toda vez que resulta ficticio suponer que el titular de la patente inscrita necesariamente habría estado dispuesto a negociar con el demandado para la utilización de la patente. Desde esta perspectiva, la norma solo contemplaría un mecanismo de cálculo para determinar el monto de las ganancias obtenidas como consecuencia del uso no autorizado de la patente, de la misma forma que ocurre en el caso de la comisión de ilícitos.

Ahora bien, resulta interesante analizar las consideraciones aportadas por Gordley relativas a la prevención o disuasión. Una preocupación central para el ordenamiento jurídico es que se respeten los derechos, así como también que se cumplan los contratos. En este contexto, resulta difícil comprender cómo la obligación de pagar al demandante el precio de mercado (avaluado por el tribunal) que el demandado hubiere debido pagar para obtener la autorización respectiva sería disuasivo para el demandado. ¿Por qué ello no implicaría imponer una venta forzada para el titular del derecho infringido? Gordley sugiere que se justifica el pago de un precio de mercado en este caso porque el titular del derecho no debiera tener la prerrogativa de negarse o cobrar precios excesivos para otorgar la autorización, en virtud del concepto funcional de la propiedad. Sin embargo, al verse obligado el demandado a solo pagar el precio de mercado, no habría diferencia alguna para este entre negociar en forma previa con el titular del derecho, o pagar posteriormente el precio determinado por el tribunal. Se requiere, entonces, de otro mecanismo para asegurar el cumplimiento de los contratos. Se trata de la ya mencionada restitución de ganancias o disgorgement of profits otorgada en el caso inglés Attorney-General v Blake ${ }^{62}$ (en adelante Blake).

\subsection{Blake}

George Blake era un miembro del Servicio Secreto Británico que reveló información confidencial a Rusia entre los años 1951 y 1960. En 1961, Blake fue condenado a 42 años de prisión en Inglaterra. Sin embargo, en 1966 se escapó de la prisión y se refugió en Moscú. Posteriormente, en 1990, la editorial Jonathan Cape Ltd publicó su autobiografía titulada "No Other Choice".

60 Gordley (2006), pp. 451 y 2.

${ }^{61}$ Ello coincide con la conclusión del Tribunal Constitucional. Véase más arriba, nota 36.

62 House of Lords (2001) 1 AC 268, 27 de julio de 2000. 
La publicación del libro violaba la Official Secret Act de 1989, así como una prohibición expresa en el contrato de trabajo de Blake de 1944, la cual establecía la prohibición de revelar cualquier información obtenida en su cargo como agente del gobierno británico. Tras una larga historia de litigación, la House of Lords en 2000 finalmente determinó que el gobierno británico tenía derecho a obtener la restitución de todas las ganancias ("disgorgement damages") que obtuvo Blake como consecuencia del incumplimiento de contrato. El caso es importante porque fue la primera vez que la House of Lords se refirió a este tipo de remedios en el ámbito contractual, aunque se negó a denominarlos expresamente como restitutorios.

Lord Nicholls redactó el voto mayoritario de la sentencia. El argumento comienza comparando la restitución de ganancias en el ámbito contractual con la restitución de ganancias obtenidas como consecuencia de ilícitos civiles contra intereses propietarios. Comenta Lord Nicholls que los derechos de propiedad son superiores a los derechos contractuales, en el sentido de que los primeros "pueden sobrevivir en contra de una clase indefinida de personas. Sin embargo, no es fácil entender por qué entre las partes de un contrato la violación del derecho contractual de una de las partes debiera conducir a un remedio de grado inferior que la violación de sus derechos de propiedad". ${ }^{63}$ El razonamiento de la sentencia es el siguiente: si el demandado infringe un derecho de propiedad del demandante, debe restituir las ganancias obtenidas como consecuencia de dicha infracción; del mismo modo, si el demandado infringe un derecho contractual del demandante, también debiera restituir las ganancias obtenidas como consecuencia de dicha infracción. No pareciera existir una razón normativa por la cual este tipo de infracciones debieran merecer un tratamiento diferenciado.

Sin embargo, el fallo advierte con claridad que se trata de un mecanismo excepcional, puesto que también se trataba de un caso excepcional. Precisamente, como señala Burrows, el punto crucial aquí consiste en determinar cuán excepcional es en definitiva este mecanismo. ${ }^{64}$ Lord Nicholls no establece "reglas precisas" para determinar en qué casos de incumplimiento contractual sería procedente la restitución de ganancias. Se señala que "la corte deberá tomar en cuenta todas las circunstancias" del caso particular, lo cual incluye considerar "el objeto del contrato, el propósito que tenía la cláusula incumplida, las circunstancias en las cuales ocurrió el incumplimiento, las consecuencias del incumplimiento y las circunstancias en las cuales se persigue el remedio" ${ }^{65}$

63 Attorney-General v Blake (2000), p. 283.

64 Burrows (2007), p. 670.

65 Attorney-General v Blake (2000), p. 285. 
Sin perjuicio de ello, Lord Nicholls establece un criterio específico para estos efectos: que el demandante tenga un interés legítimo en el cumplimiento de la cláusula que ha sido incumplida. Se trata de un requisito aplicable solo a la restitución de ganancias obtenidas como consecuencia de un incumplimiento contractual, y no para los demás casos de restitución de ganancias obtenidas como consecuencia de un ilícito civil.

De acuerdo a Lord Nicholls, este requisito del interés legítimo en el cumplimiento de la cláusula contractual se requiere para solicitar una restitución de ganancias de la misma manera que se requiere un interés legítimo para solicitar el cumplimiento forzado de un contrato. Cabe aclarar que en el derecho inglés de los contratos (y en la mayoría de los sistemas del common law), el cumplimiento forzado del contrato es un remedio excepcional; la regla general es la indemnización de perjuicios. En algunos casos puede resultar complejo determinar si existe o no un interés legítimo del demandante para el cumplimiento del contrato, pero lo que queda claro es que este interés legítimo no existe en aquellos casos en los cuales la cláusula contractual incumplida no daría lugar a una orden judicial (injunction) o a decretar un cumplimiento forzado. Ello excluye, como acota Edelman, incumplimientos contractuales triviales, así como también aquellos contratos de servicios personales en los cuales decretar el cumplimiento forzado restringiría más allá de lo razonable la libertad del demandado. ${ }^{66}$ Por otra parte, se ha señalado que el cumplimiento forzado del contrato debiera decretarse en los casos en los cuales el bien o la prestación objeto del contrato es difícil de reemplazar porque tiene alguna singularidad especial. ${ }^{67}$

Como ya señalé anteriormente, en Blake se enfatiza que se trata de un mecanismo aplicable "solo en circunstancias excepcionales". ${ }^{68}$ Adicionalmente al requisito del interés legítimo del demandante para exigir el cumplimiento del contrato, Lord Nicholls también señala que el mecanismo es procedente solo en el evento que los demás remedios (la indemnización de perjuicios, el cumplimiento forzado del contrato, o una orden judicial) sean "inadecuados" ${ }^{69}$ Para Edelman, el caso paradigmático de esta condición lo constituyen los incumplimientos cínicos (o intencionales) de contratos. ${ }^{70}$ Sin embargo, Lord Nicholls advierte que la sola circunstancia de que un contrato haya sido incumplido in-

\footnotetext{
${ }^{66}$ Edelman (2002), p. 158.

67 KRONMAN (1978).

${ }^{68}$ Attorney-General v Blake (2000), p. 285.

69 Attorney-General v Blake (2000), p. 285.

70 Edelman (2002), p. 158.
} 
tencionalmente, por sí misma, no debiera dar lugar a la restitución de ganancias; lo mismo se señala respecto al hecho que el incumplimiento del contrato le permitió al demandado poder ejecutar otro contrato más lucrativo para él. ${ }^{71}$ Por ello es que la restitución de ganancias es un remedio excepcional; no solo basta con un incumplimiento de contrato intencional, sino que se requiere además la existencia de un interés legítimo del demandante para exigir el cumplimiento del contrato. En este caso, se estimó que el gobierno británico tenía un interés legítimo en prevenir que Blake se beneficie con revelar información que obtuvo mientras trabajaba como agente del gobierno. Una regla contraria, señala Lord Nicholls, "pondría en riesgo la efectividad del servicio". ${ }^{72}$

Hasta la fecha existen dudas en la doctrina inglesa respecto a Blake. Desde luego, se trata de un caso excepcional, y por lo mismo, podría resultar discutible obtener conclusiones generales a partir de un caso con tantas particularidades. Sin embargo, también resulta interesante destacar que la solución adoptada por la House of Lords es la misma que la Corte Suprema estadounidense había adoptado veinte años antes en un caso sorprendentemente similar. ${ }^{73}$ Asimismo, una sentencia judicial posterior a Blake aclara que la restitución de ganancias obtenidas como consecuencia de un incumplimiento contractual puede ser decretada aún tratándose de relaciones comerciales, y en circunstancias menos excepcionales o inusuales que la de un espía escribiendo sus memorias. ${ }^{74}$

\subsection{Lecciones de Wrotham Park y Blake}

¿Qué podemos aprender de este desarrollo jurisprudencial inglés (relativamente reciente) de la restitución de ganancias obtenidas como consecuencia de un incumplimiento contractual? Pareciera ser que persisten las dos líneas argumentativas de los casos Wrotham Park y Blake. Por una parte, siguiendo a Wrotham Park, todos los casos en que se ha decretado la restitución de ganancias pueden ser descritos como el pago de una suma de dinero equivalente a lo que

\footnotetext{
71 Attorney-General v Blake (2000), p. 286.

72 Attorney-General v Blake (2000), p. 287.

73 Snepp v United States (1980), United States Supreme Court, 444 U.S. 507, 62 L.Ed.2d 704, 19 de febrero de 1980.

${ }^{74}$ Esso Petroleum Company Limited v Niad Limited (2001), Chancery Division, [2001] EWHC Ch 458, 22 de noviembre de 2001. Se trataba de un concesionario (Niad) de la compañía Esso que violó su contrato de concesión infringiendo el esquema fijo de precios (Ilamado "Pricewatch") establecido por Esso para todos sus concesionarios. Niad se benefició incumpliendo su contrato al cobrar precios superiores a los fijados por Esso. Se estimó que la indemnización de perjuicios era inadecuada para remediar el incumplimiento, toda vez que a Esso le resultaba imposible probar que había sufrido pérdidas en sus ventas como consecuencia del incumplimiento de Niad. La Corte decretó que Esso tenía derecho, a su elección, a una indemnización de perjuicios o la restitución de ganancias.
} 
la parte incumplidora habría tenido que pagarle a su contraparte para los efectos de relajar la cláusula del contrato que se ha infringido. ${ }^{75}$ Sin embargo, como se ha señalado anteriormente, en muchos casos ello resulta ficticio (incluso en el mismo caso Wrotham Park). Por ejemplo, resulta casi imposible pensar que el gobierno británico hubiera autorizado a Blake a revelar la información a cambio de una suma de dinero. La perspectiva de Wrotham Park no cubre aquellos casos en los cuales la parte demandante no habría estado dispuesta a negociar una relajación de la cláusula contractual que fue incumplida. Para estos casos es, a mi juicio, necesario recurrir a una acción de naturaleza definitivamente restitutoria, siguiendo la línea argumentativa de Blake.

Los casos en los cuales se decreta el pago de una suma de dinero equivalente a lo que habría estado dispuesto a aceptar la parte cumplidora para relajar la cláusula del contrato respectivo no representan mayores problemas para nuestro ordenamiento jurídico. Sin perjuicio de que, siguiendo a Burrows y Edelman, la naturaleza jurídica de estos pagos corresponde más propiamente a acciones restitutorias y no indemnizatorias, en nuestro ordenamiento jurídico ellos podrían ser decretados para efectos de calcular las indemnizaciones de perjuicios respectivas. Ello permitiría, por ejemplo, eliminar la incertidumbre que podría implicar avaluar un eventual daño moral en un caso como Wrotham Park, en el cual podría estimarse que los demandantes sufrieron un daño moral con la construcción no autorizada de viviendas. En cambio, el pago de la suma de dinero equivalente a lo que habrían negociado hipotéticamente las partes para relajar la cláusula del contrato, calculada sobre la base de las ganancias obtenidas por el demandado, le da una base objetiva de cálculo a una indemnización por lucro cesante. Se trataría de lucro cesante por consistir en la suma de dinero que los demandantes habrían dejado de percibir como consecuencia del incumplimiento de contrato. Ello es, como se señaló anteriormente, consistente con la solución planteada por las letras b) y c) del artículo 108 de la Ley No 19.039, de 1991.

Sin embargo, en aquellos casos en los cuales el demandante no habría estado dispuesto a negociar para relajar la cláusula que fue incumplida, este ejercicio resulta artificioso. ${ }^{76}$ Podemos suponer que ello ocurre en nuestro ejemplo hipotético, en el cual Cola-Cola difícilmente habría estado dispuesta a llevar a cabo una negociación para autorizar a Carlos para vender su fórmula secreta. ¿Cómo es posible solucionar este tipo de casos? En atención a que en nuestro

${ }^{75}$ En el mismo caso Blake, el voto disidente de Lord Hobhouse sugiere esta perspectiva, rechazando la procedencia de la restitución de ganancias. Attorney-General v Blake (2000), pp. 293-99.

${ }^{76}$ También resultaría, en mi opinión, artificioso e impreciso argumentar que en un caso como Blake el gobierno británico sufrió un daño moral. 
sistema jurídico el cumplimiento forzado del contrato no es un mecanismo excepcional para remediar un incumplimiento de contrato, el primer requisito de Blake (interés legítimo del demandante en el cumplimiento del contrato) no es aplicable. Queda por determinar, entonces, en qué casos sería procedente decretar una restitución de ganancias cuando la indemnización de perjuicios es inadecuada (o en palabras más simples, cuando no hay perjuicios para el demandante como consecuencia del incumplimiento del contrato, o cuando las ganancias superan los perjuicios causados). La solución radica, a mi juicio, en el principio que podemos extraer del artículo 1558 del Código Civil, según el cual un incumplimiento contractual meramente negligente no puede tener las mismas consecuencias que un incumplimiento doloso o gravemente negligente. Solo cuando estamos en presencia de un incumplimiento doloso debiera ser procedente la restitución de ganancias obtenidas como consecuencia del incumplimiento contractual.

Ahora bien, para configurar una hipótesis de "incumplimiento doloso de contrato" no debiera requerirse una intención positiva de causar daño a la contraparte. Imponer tal requisito restringiría en demasía las hipótesis de restitución de ganancias. El mismo caso Blake no quedaría cubierto bajo esta interpretación, puesto que Blake no necesariamente tenía la intención de causar perjuicios al gobierno británico. Sería, adicionalmente, un despropósito exigir intención positiva de causar daño o malicia (como pudiera desprenderse de una interpretación literal del artículo 44 del Código Civil), cuando en la mayoría de estos casos no se ha causado daño alguno. ${ }^{77} \mathrm{~A}$ mi juicio, lo que debiera exigirse es que el incumplimiento sea intencional, pero no necesariamente con la expresa intención de causar daño, excluyendo en consecuencia aquellas hipótesis de incumplimientos meramente accidentales o negligentes (salvo culpa grave) y, por cierto, las hipótesis de incumplimientos causados por fuerza mayor o caso fortuito. Bastaría, en palabras de Hernán Corral Talciani, con "que el sujeto se haya representado como posible el resultado lesivo y lo haya querido, aunque a su pesar, como resultado directo de su acción" ${ }^{78}$

¿Cómo podría justificarse la restitución de ganancias en un ordenamiento jurídico como el chileno que carece de una norma expresa que lo contemple? Cabe preguntarse, en primer lugar, la razón por la cual las ganancias obtenidas

\footnotetext{
77 Refuerza esta idea el hecho que el artículo 44 señale como una hipótesis de dolo la intención positiva de inferir injuria a otro, esto es, la intención de violar un derecho del otro que no necesariamente se traduce en un daño. Véase más arriba, nota 38.

${ }^{78}$ Corral (2013), p. 205. En el mismo sentido, Katy Barnett sugiere la noción de incumplimiento voluntario [advertent breach], según la cual lo importante es determinar "si el demandado consciente $o$ voluntariamente desconoció los derechos del demandante". BARNETT (2012), p. 44.
} 
como consecuencia de un ilícito civil que infringe derechos propietarios daría lugar (al menos de acuerdo a la doctrina) a una acción restitutoria, mientras que las ganancias obtenidas como consecuencia de un incumplimiento contractual no daría lugar a dicha acción. Se produciría la misma injusticia que, antes de 1994, se producía en la jurisprudencia chilena al admitirse la indemnización del daño moral solo en el ámbito de la responsabilidad extracontractual, o admitiéndose solo para el caso de un contrato en particular. ${ }^{79}$

En segundo lugar, existen hipótesis dentro del Código Civil y también en leyes especiales que son consistentes con la procedencia de este mecanismo cuando estamos en presencia de incumplimientos contractuales dolosos (o gravemente culpables), en los términos antes referidos. Así, como ya he señalado, el artículo 1558 del Código Civil provee una base al principio según el cual estos incumplimientos no deben tener las mismas consecuencias que aquellos incumplimientos de contrato en que no hay dolo. Asimismo, un sustento normativo adicional para la procedencia de la restitución de ganancias obtenidas como consecuencia de un incumplimiento doloso de contrato se encuentra en los artículos 1458 y 2316 del Código Civil, de los cuales me ocuparé a continuación.

\section{Restitución de ganancias obtenidas como consecuencia del dolo ajeno}

¿Es posible situar la acción de los artículos 1458 y 2316 del Código Civil en el marco teórico de la restitución de ganancias formulado en las secciones anteriores? En los casos Inverlink, los demandantes basaron su acción en el artículo 2316 del Código Civil. A pesar de que el Código Civil regula esta acción a propósito de las reglas de responsabilidad extracontractual, se trata de una hipótesis restitutoria y no indemnizatoria. Así lo señaló correctamente la Corte Suprema: "aun cuando se está en presencia de una acción derivada de la responsabilidad extracontractual, ella no tiene la naturaleza de una acción indemnizatoria propiamente tal, ya que la obligación de restituir no está determinada por el monto de los perjuicios sufridos". ${ }^{80}$ La calificación restitutoria que la Corte le otorga a la acción es importante dado que se trataba de una

\footnotetext{
79 Un recuento de la evolución jurisprudencial en esta materia puede encontrarse en DomínGUEZ (2000), p. 335.

${ }^{80}$ Corte Suprema, Rol № 4871-2012, 30 de septiembre de 2013, c. $22^{\circ}$. En la sentencia Corte Suprema, Rol No 6302-2010, 30 de enero de 2013, esta opinión no fue compartida por el abogado integrante Jorge Baraona G., quien en el punto cuarto de su voto disidente señala: "no puede aceptarse la doctrina que estima que en este caso estemos frente a una acción restitutoria, pues la norma recién citada, es decir el artículo 2316 del Código Civil, se refiere con toda claridad a los que están obligados a la indemnización, con lo cual es patente que lo que se busca es la reparación del daño".
} 
materia controvertida en doctrina. ${ }^{81} \mathrm{~A}$ pesar de que escapa al propósito de este trabajo defender acabadamente la postura adoptada al respecto, cabe señalar que la Corte acertadamente califica la acción como restitutoria principalmente porque el monto a restituir se calcula sobre la base del provecho obtenido por el tercero y no los perjuicios causados a la víctima del dolo. ${ }^{82}$ Esta característica es la que asimila la acción del provecho por dolo ajeno a la hipótesis del artículo 108 letra b) de la Ley № 19.039, de 1991, y a los mecanismos de restitución de ganancias ilícitas establecidos en el common law que se examinaron en las secciones anteriores.

Para la Corte, los requisitos para que sea procedente esta acción restitutoria por el dolo ajeno son los siguientes:

1. que exista una acción dolosa;

2. que un tercero reciba provecho de ese dolo ajeno; y

3. que el que recibe el provecho no sea cómplice del dolo.

Como ya se advirtió anteriormente, lo interesante de esta hipótesis contemplada por el Código Civil es que el monto a pagar por el demandado se encuentra determinado exclusivamente por los beneficios o el provecho que se ha obtenido por la comisión del dolo. De hecho, la norma enfatiza el hecho que el demandado "sólo es obligado hasta concurrencia de lo que valga el provecho". Ello se justifica porque la norma exige que el tercero que se aprovecha del dolo no sea cómplice en la comisión del dolo, evento en el cual sería responsable también solidariamente por los daños ocasionados por la comisión del dolo (artículo 2317). En definitiva, para que sea procedente la acción restitutoria del artículo 2316, no se requiere la existencia de un perjuicio para el demandante; es el provecho o ganancias obtenidas como consecuencia de la comisión del dolo lo que determina la procedencia de la acción. ${ }^{83}$. De lo anterior se desprende que la acción restitutoria no depende de una eventual acción de responsabilidad extracontractual en contra del autor del daño. En este sentido, me parece que incurre en un error la sentencia de la Corte Suprema cuando señala que "igualmente es necesario que se produzca un daño a la víctima, pero

\footnotetext{
${ }^{81}$ A favor de la calificación restitutoria, Barros (2006), p. 932; PIZARRo (2009), p. 682 a favor de la calificación indemnizatoria, Domínguez Águila (2009), p. 223, y de forma más tenue, CHADWICK (1933), p. 69 (a pesar de que en ocasiones señale expresamente que se trata de una "acción de restitución", p. 67).

${ }^{82}$ Ello no implica que se trate de una acción subsidiaria, sino que se trata de una acción legal directa en contra de quien se aprovecha del dolo ajeno, y en ello la acción se distingue de la acción de enriquecimiento injustificado propiamente tal. CHADwick (1933), p. 70. Sin embargo, a mi juicio ello no conduce a la conclusión de que la naturaleza de la acción sea indemnizatoria, como sugiere Ramón Domínguez Águila. Domínguez (2009), pp. 221 y 2.

${ }^{83}$ En el mismo sentido, señala Pizarro Wilson que "no hay una real conexión entre el daño ocasionado a la víctima y la acción para el pago del provecho". PizArRo (2009), p. 682.
} 
este sólo opera como factor de delimitación del monto máximo a restituir" ${ }^{84}$ Dicha conclusión no se desprende de los artículos 1458 o 2316, y es contraria a su naturaleza restitutoria. ${ }^{85} \mathrm{El}$ único factor que delimita el monto máximo a restituir es la conexión de causalidad entre el provecho o ganancias obtenidas por el demandado (el tercero) y el dolo cometido por un agente distinto al demandado. Como señala Arturo Alessandri Rodríguez, el fundamento de este artículo reside en que "[l]a ley no admite que el dolo pueda ser fuente legítima de lucro para alguien". ${ }^{86}$

Como puede apreciarse, se trata de una hipótesis en la cual se contempla la restitución de ganancias obtenidas como consecuencia de la comisión de un acto ilícito civil y doloso, sin que se requiera la concurrencia de una pérdida correlativa a la ganancia obtenida por el demandado. De acuerdo a lo señalado en la segunda sección, se trataría entonces de aquellas hipótesis de enriquecimiento injustificado cuyo fundamento reside principalmente en la prevención o disuasión, y no en la justicia correctiva. ${ }^{87}$ La Corte destaca que la acción "constituye una excepción en materia de responsabilidad extracontractual", siendo una obligación "que nace en virtud de la ley, que es su fuente jurídica, sin perjuicio de que el fundamento último de ella reside en el enriquecimiento injusto, el cual no es admitido por el legislador". ${ }^{88}$ Me parece que la Corte también incurre aquí en un error al sostener que se trata de una regla excepcional en materia de responsabilidad extracontractual, puesto que la naturaleza de la acción es restitutoria y no indemnizatoria (a menos que la Corte Suprema simplemente haya querido sostener que se trata de una acción restitutoria "excepcionalmente" o mal ubicada en el párrafo del Código Civil que regula las normas sobre responsabilidad extracontractual). En consecuencia, la acción no es una regla excepcional del régimen de responsabilidad extracontractual, sino que se trata de una aplicación del principio del enriquecimiento injustificado. Precisamente son estas hipótesis las que permiten sostener que el principio del enriquecimiento injustificado sí es admitido por el legislador. De manera tal que es posible sostener que la existencia de esta acción restitutoria le otorga un sustento legal a lo sugerido en la sección anterior, en términos de que se-

\footnotetext{
${ }^{84}$ Corte Suprema, Rol No 4871-2012, de 30 de septiembre de 2013, c. $22^{\circ}$.

${ }^{85}$ En este sentido, resulta revelador que para quienes la acción tiene una naturaleza indemnizatoria, es requisito para interponer la acción que la víctima haya sufrido perjuicios como consecuencia del acto doloso. Chadwick (1933), p. 67; Domínguez (2009), pp. 223 y 4.

86 Alessandri (1943), p. 348.

${ }^{87}$ A menos que se entienda la noción de pérdida en un sentido normativo, o que se adopte una noción más amplia de justicia correctiva.

${ }^{88}$ Corte Suprema, Rol No 4871-2012, de 30 de septiembre de 2013, c. $22^{\circ}$.
} 
ría posible en general decretar la procedencia de la restitución de ganancias obtenidas como consecuencia de un incumplimiento contractual que ha sido cometido con dolo. Si ello es cierto, entonces la acción dejaría de tener tal carácter excepcional en nuestro ordenamiento jurídico.

\section{La concurrencia de acciones restitutorias e indemnizatorias}

La pregunta que persigue responder la presente sección se origina como consecuencia de la calificación de la acción del provecho por dolo ajeno como restitutoria, ${ }_{1}^{89}$ pero en general puede plantearse en general respecto de todas las acciones de restitución de ganancias ilícitas. La pregunta tiene que ver con la concurrencia o cúmulo de acciones indemnizatorias y restitutorias: ¿qué ocurre si en los casos de restitución de ganancias que se han analizado en las secciones anteriores existen daños para la víctima además de ganancias ilícitamente obtenidas para el demandado? ¿Es posible entablar una acción restitutoria y posteriormente una indemnizatoria, o viceversa, para recuperar tanto las pérdidas como las ganancias? Ello es particularmente relevante para el caso de la acción restitutoria de los artículos 1458 y 2316 del Código Civil. El demandado es obligado solo al pago del provecho que obtuvo como consecuencia de la comisión del dolo, de manera tal que no es obligado a pagar los perjuicios que puede o no haber sufrido el demandante como consecuencia del ilícito. Si el demandante pretende ser indemnizado por estos perjuicios, deberá entablar la acción de responsabilidad extracontractual correspondiente en contra de quien fraguó el dolo. En el caso de Inverlink, la Corfo demandó a los terceros y no a Inverlink (empresa que fraguó el daño) por una razón práctica: al momento de interponer la demanda, Inverlink había sido declarada en quiebra. Difícilmente Corfo podría haber obtenido, en la práctica, una indemnización de perjuicios por parte de una empresa insolvente. Sin embargo, es posible perseguir la responsabilidad penal y civil de las personas que directamente fraguaron el dolo. En efecto, así ha procedido recientemente la Corfo. ${ }^{90} \mathrm{Si}$ se siguen acogiendo (y se confirman por la Corte Suprema) acciones indemnizatorias por daño emergente a favor de Corfo directamente en contra de quienes fraguaron el dolo, se vuelve más necesario realizar el análisis que sigue a continuación, en términos de analizar si es procedente aceptar la concurrencia o cúmulo de las acciones indemnizatorias y restitutorias sobre un mismo hecho. ${ }^{91}$

\footnotetext{
${ }^{89}$ Si se estima que la acción tiene una naturaleza indemnizatoria, el problema no se presenta: la víctima solo podría recobrar la indemnización por el monto de sus perjuicios.

${ }^{90}$ Ver, por ejemplo, Corte de Apelaciones de Santiago, Rol № 2227-2013, de 2 de diciembre de 2014.

${ }^{91}$ Teniendo en cuenta además la elevada suma de \$26.462.295.646 que obtuvo Corfo por daño emergente mediante este litigio que acaba de ser fallado por la Corte de Apelaciones de Santiago.
} 
También resulta interesante plantearse esta pregunta desde el punto de vista teórico, puesto que ella no solo es aplicable a esta acción restitutoria, sino que también puede plantearse respecto a cualquier hipótesis en la cual sea procedente la restitución de ganancias.

Para Pizarro Wilson, "el daño no importa a efectos de fijar la cuantía del provecho, ni tampoco corresponde imputarlo".$^{92}$ Sin perjuicio de que el asunto es discutible, no concuerdo con esta última afirmación. Si bien como vimos, el daño no constituye un requisito para la procedencia de la acción restitutoria de los artículos 1458 y 2316, en caso que exista un daño ocasionado por el dolo no debiera ser posible para la víctima obtener la restitución de las ganancias obtenidas por el tercero que no participa en la comisión del ilícito, y a la vez obtener la indemnización de todos los perjuicios sufridos por parte del autor del daño (quien fraguó el dolo). De permitirse esta situación se configuraría, en mi opinión, un doble pago. Ello ocurre no solo en el caso de la acción restitutoria por dolo ajeno, sino también en las otras hipótesis de restitución de ganancias obtenidas como consecuencia de un ilícito civil o de un incumplimiento contractual. A mi juicio, cualquier respuesta que se plantee respecto a la concurrencia de acciones debiera ser la misma para todos estos casos. ¿Por qué habría de ser diferente la respuesta para el caso de la acción restitutoria por dolo ajeno? ¿Solo por el hecho de que quien pagaría la eventual indemnización de perjuicios (quien fraguó el dolo) sería una persona distinta de quien restituiría las ganancias obtenidas (el tercero que no participa en la comisión del ilícito)? Ello no parece constituir una razón normativa de suficiente peso como para establecer un diferente tratamiento; más aún considerando que los sistemas modernos de responsabilidad extracontractual conviven en la práctica con sistemas de seguros, en virtud de los cuales quien paga en definitiva no es el agente que causó el daño sino un tercero. ${ }^{93}$

Podemos volver aquí a los ejemplos utilizados anteriormente para explicar las demás hipótesis de restitución de ganancias. Pedro utiliza el caballo Rocinante (avaluado en \$50) de propiedad de Juan sin pedirle a este su autorización, y obtiene una ganancia producto de ello (equivalente a \$100), pero en esta ocasión, después de la carrera Rocinante se lesiona gravemente y muere. La situación podría remediarse, desde luego, interponiendo Juan una acción de responsabilidad extracontractual en contra de Pedro, solicitando la indemnización de perjuicios respectiva. Dicha indemnización debiera cubrir tanto el daño material causado (es decir, el valor comercial que tenía Rocinante de \$50), el

92 Pizarro (2009), p. 682.

93 El mismo punto es destacado por Ramón Domínguez Águila, aunque con un propósito distinto (para defender la naturaleza indemnizatoria de la acción). Domínguez (2009), p. 223. 
lucro cesante (debiendo calcularse el valor de las ganancias que, en circunstancias normales, Juan habría obtenido con Rocinante), e incluso un eventual daño moral (por el valor afectivo que podría haber tenido Rocinante para Juan). El monto total a indemnizar podría ser superior a las ganancias obtenidas por Pedro con el ilícito; pero en otros casos es posible que las ganancias obtenidas sean superiores a los daños causados (especialmente si Rocinante no muere y solo resulta herido por un par de meses, por ejemplo). ¿Sería posible para Juan interponer una acción restitutoria en contra de Pedro adicionalmente a la indemnizatoria?

La misma pregunta puede plantearse respecto a una acción que persiga restituir las ganancias obtenidas como consecuencia de un incumplimiento contractual. Nuevamente, en nuestro ejemplo Carlos, contratista de Cola-Cola vende la fórmula secreta de una de sus bebidas a su competidor Pep-Cola, violando el contrato suscrito por ambos. Pero supongamos ahora que Cola-Cola sufrió efectivamente un daño, pero que es inferior a las ganancias obtenidas por Carlos como consecuencia de la venta de la fórmula. ¿Es posible para Cola-Cola solicitar la indemnización de perjuicios, y adicionalmente solicitar la restitución de las ganancias obtenidas por Carlos con la venta de la fórmula secreta, en contravención al contrato suscrito por las partes?

En mi opinión, solo dos soluciones que evitan el doble pago por el mismo hecho pueden adoptarse a este respecto. La primera solución es aquella adoptada por el derecho inglés: no pueden interponerse ambas acciones, el demandante debe elegir una de ellas (probablemente, la que sea más conveniente para él). ${ }^{94}$ Una segunda solución consiste en permitir la interposición de ambas acciones, pero debiendo imputarse en el monto a pagar lo que procediere pagarse en virtud de la otra acción. En otras palabras, esta solución implicaría deducir del monto a indemnizar el monto pagado en virtud de la acción restitutoria y viceversa, esto es, deducir del monto a restituir el monto pagado en virtud de la acción indemnizatoria. Por razones prácticas, me inclino por la primera solución: debiera ser el demandante quien debiera determinar la acción que le resulte más conveniente para remediar el ilícito cometido en su contra. A mayor abundamiento, esta solución, como veremos más adelante, tiene un sustento legal en nuestro ordenamiento jurídico.

Pero antes que ello, vale la pena cuestionarse ipor qué obtener una indemnización de perjuicios y adicionalmente la restitución de las ganancias por el mismo hecho constituiría un doble pago para la víctima? La clave para responder esta pregunta reside en el fundamento de justicia correctiva y la correlatividad de ganancias y pérdidas en que se sustenta la responsabilidad extracontractual.

94 Burrows (2007), p. 627. 
Como vimos, resulta discutible sostener que en todas las hipótesis de enriquecimiento injustificado debe existir correlatividad entre las ganancias obtenidas por el demandado y las pérdidas sufridas por el demandante (porque en muchos casos no hay pérdidas para el demandante). A la inversa, en la responsabilidad extracontractual resulta discutible sostener que existe siempre una ganancia para el demandado al cometer el ilícito civil. Los teóricos de la justicia correctiva han elaborado diversas formas de solucionar este problema que permitirían sostener que no se trata de una objeción insalvable para la justicia correctiva. Sin embargo, cualquiera sea la solución adoptada, algunas hipótesis de restitución de ganancias no pueden ser cubiertas por el fundamento normativo de la justicia correctiva. Ello se presenta en aquellos casos en los cuales el fundamento de las acciones restitutorias reside en la prevención de la comisión de ilícitos, y no en compensar a las víctimas por los daños sufridos como consecuencia de un ilícito civil. A mi juicio, este fundamento normativo es aplicable a la restitución de ganancias obtenidas como consecuencia de un incumplimiento contractual y a la acción restitutoria de los artículos 1458 y $2316 . .^{95}$

Esta calificación, que a primera vista pudiera parecer meramente técnica o teórica, tiene consecuencias prácticas. En la responsabilidad extracontractual, la indemnización de perjuicios cumple la doble función de compensar a la víctima las pérdidas que sufrió, y al mismo tiempo restituir las ganancias que el agente del daño obtuvo con la comisión del ilícito. Como señala acertadamente Weinrib, "un solo monto deshace la injusticia tanto respecto a lo que ha hecho el demandado, como respecto a lo que ha sufrido la víctima" ${ }^{96}$ También en los términos de la justicia correctiva como anulación de Jules Coleman, podríamos señalar que la obligación para el demandado de pagar una indemnización de perjuicios anula la injusticia que representa para el demandante tener que soportar sufrir las pérdidas causadas ilícitamente por el demandado, y a su vez anula la injusticia que implica que el demandado retenga las ganancias obtenidas ilícitamente a expensas del demandante. ${ }^{97}$

No ocurre lo mismo en aquellos casos de enriquecimiento injustificado en los cuales no hay pérdidas para el demandante. En estos casos, solo existe una

\footnotetext{
${ }^{95}$ Como vimos, autores como Ripstein y Weinrib sostienen que en la restitución de ganancias obtenidas como consecuencia de un ilícito civil que vulnera intereses propietarios existe la correlatividad entre ganancias y pérdidas requerida por la justicia correctiva. Véase más arriba notas 35 y 44 . Sin comprometerme con esta tesis, sostengo aquí que al menos para las demás hipótesis de restitución de ganancias, el fundamento normativo de la justicia correctiva no parece ser aplicable.

${ }^{96}$ WeINRIB (2012a), p. 143.

97 Coleman (1992a), p. 357. Con posterioridad, Coleman abandonó en parte su teoría de la anulación. Coleman (1992b), pp. 311 y ss.
} 
ganancia obtenida injustamente por parte del demandado; no se cumple entonces el requisito de correlatividad de la justicia correctiva. La acción restitutoria para cobrar las ganancias obtenidas injustamente por el demandado tiene un fundamento principalmente preventivo o disuasivo, como se ha argumentado en el presente trabajo. Sin embargo, en el evento que existan daños para el demandado, la situación cambia. Volvamos a los ejemplos para aclarar este punto. Si el caballo Rocinante no resulta dañado como consecuencia de la carrera, es procedente una acción de enriquecimiento injustificado por uso indebido de propiedad ajena. Ahora bien, si Rocinante es dañado como consecuencia de participar en la carrera, Juan deberá elegir entre interponer una acción de responsabilidad extracontractual en contra de Pedro por los perjuicios sufridos en su propiedad (equivalentes a \$ 50 más el lucro cesante y, eventualmente, el daño moral), o interponer una acción restitutoria por las ganancias obtenidas con el uso indebido de propiedad ajena (\$100). Permitir la interposición conjunta de estas acciones implica una contradicción con la correlatividad de ganancias y pérdidas en la responsabilidad extracontractual y su fundamento en justicia correctiva; al perseguir Juan la indemnización de perjuicios, el sistema jurídico obliga a Pedro a pagar dicha indemnización porque supone que se ha beneficiado al cometer el ilícito. Es irrelevante si este beneficio se traduce en un provecho material o normativo; en ambos casos, Pedro deberá pagarle a Juan la indemnización de perjuicios respectiva.

En nuestro ejemplo contractual ocurre lo mismo. Si Cola-Cola sufre daños (o logra probar que sufrió daños) como consecuencia del incumplimiento contractual de Carlos, podrá interponer una acción de responsabilidad contractual en contra de Carlos solicitando la indemnización de perjuicios respectiva (conjuntamente con la resolución del contrato, si fuere procedente). Nuevamente, resulta incompatible con esta acción una acción restitutoria por parte de ColaCola, toda vez que el pago de la indemnización de perjuicios por parte de Carlos anula o elimina al mismo tiempo la injusticia que implica para Cola-Cola sufrir los daños, y para Carlos el retener las ganancias obtenidas por la venta de la fórmula secreta. La existencia de un tercero que se beneficia con el dolo ajeno (Pep-Cola, suponiendo que se encuentra de buena fe) no debiera modificar esta conclusión. Sería absurdo sostener que por el solo hecho de que en este caso el provecho o ganancia lo recibe un tercero y no quien comete el ilícito justifica la interposición de ambas acciones. El mismo razonamiento debiera ser aplicable para ambas circunstancias..$^{98}$

\footnotetext{
${ }_{98}$ Así también, siguiendo este razonamiento debiera ser posible otorgar una acción restitutoria en contra del autor del dolo (y no solamente en contra del tercero inocente), cuando este ha obtenido ganancias con la comisión del ilícito civil que superan las pérdidas provocadas a la víctima. La sola
} 
Es importante destacar aquí que la restricción del pago doble se aplica siempre y cuando exista un vínculo causal entre el hecho que motiva la acción indemnizatoria y el hecho que motiva la acción restitutoria. En otras palabras, debe tratarse del mismo hecho el que origina las pérdidas y ganancias. Lo determinante para que sea aplicable la restricción del doble pago es que se trate del mismo hecho el que sirve de fundamento para la interposición de ambas acciones. Así, por ejemplo, si Rocinante se lesiona con posterioridad por un hecho distinto a la carrera (que es el hecho generador de la ganancia de Pedro), una acción indemnizatoria sería compatible con la acción restitutoria, toda vez que cada una de ellas tiene un hecho generador independiente, o no están causalmente conectadas.

Corresponde aquí hacerse cargo de dos objeciones en contra de esta restricción del doble pago. La primera objeción puede ser formulada en los siguientes términos: el sistema jurídico en muchas ocasiones permite que las víctimas reciban dobles pagos. Ejemplo de ello lo constituyen los beneficios que una víctima puede recibir en virtud de un contrato de seguro privado. ¿Por qué este caso debiera ser distinto $?^{99} \mathrm{~A}$ mi juicio, la situación es distinta. En los casos en que hay seguros involucrados, la pregunta es si el sistema jurídico debiera tomar en cuenta en el juicio de responsabilidad civil una situación contractual entre un tercero (la aseguradora) y la víctima. En la acción del provecho por dolo ajeno también se involucra a un tercero, pero se trata de un tercero que (en principio) no tiene relación contractual alguna con la víctima. Se trata además de un tercero inocente que, a diferencia de una aseguradora, difícilmente pudo calcular y prever los riesgos que involucraba la operación que dio origen al aprovechamiento.

La segunda objeción tiene que ver con los distintos fundamentos que justifican una u otra acción. Si la acción de responsabilidad extracontractual se fundamenta en la justicia correctiva y la acción del provecho por dolo ajeno se fundamenta en la prevención o disuasión, ipor qué sería incompatible su interposición conjunta? En primer lugar, como ya se señaló en la sección segunda, resulta problemático sostener que la responsabilidad extracontractual responde exclusivamente a fundamentos de justicia correctiva. ${ }^{100}$ Es indudable que la responsabilidad extracontractual también responde a otros fines, por ejemplo

circunstancia de que sea un tercero y no el autor del dolo el que recibe el provecho no debiera, a mi juicio, ser obstáculo para que sea aplicable una acción restitutoria. Se trata de una materia que escapa de los alcances del presente artículo, pero que valdría la pena desarrollar con más detalle.

99 Agradezco a Cristián Banfi del Río por la formulación de esta objeción.

100 Por eso se argumentó que la justicia correctiva constituye un requisito necesario pero no suficiente para la justificación de la responsabilidad extracontractual. Véase más arriba nota 14. 
punitivos o retributivos. ${ }^{101}$ En segundo lugar, tanto la acción restitutoria como la indemnizatoria comparten un mismo supuesto, que consiste en la existencia de una ganancia que se origina como consecuencia de la comisión de un ilícito. Como ya se ha señalado, en la acción de responsabilidad extracontractual la indemnización de perjuicios compensatoria anula al mismo tiempo tanto las pérdidas como las ganancias generadas por el hecho ilícito. Ello explica la razón por la cual es incompatible la interposición conjunta de ambas acciones frente a cada ilícito extracontractual. Dicha situación no cambia por el solo hecho de tratarse de un tercero el sujeto pasivo de la acción, toda vez que el hecho que origina la acción restitutoria es igualmente el hecho doloso que genera la acción indemnizatoria.

Finalmente, cabe señalar que la restricción del doble pago aquí defendida tiene un sustento legal en el artículo 108 de la Ley $\mathrm{N}^{\circ} 19.039$, de $1991 .{ }^{102} \mathrm{La}$ norma establece que el demandante puede solicitar la indemnización de perjuicios respectiva, pero deberá elegir como base de cálculo entre "las utilidades que el titular hubiere dejado de percibir como consecuencia de la infracción" (letra a), "las utilidades que haya obtenido el infractor como consecuencia de la infracción" (letra b), o "el precio que el infractor hubiere debido pagar al titular del derecho por el otorgamiento de una licencia" (letra c). Ya se ha señalado con anterioridad que en la segunda hipótesis (letra b) se trata más propiamente de una restitución y no de una indemnización, y que en el tercer caso (letra c) resulta discutible su calificación jurídica. Pero lo que es claro es que la disposición no permite la interposición conjunta de una acción restitutoria e indemnizatoria; se asume correctamente que una indemnización de perjuicios corrige tanto la injusticia que representa el soportar las pérdidas para la víctima, como la injusticia que implica permitirle al infractor de la propiedad industrial retener las ganancias obtenidas con la infracción.

\section{Conclusiones e implicancias}

La ambición del presente trabajo consiste en plantear un marco teórico para la hipótesis de los artículos 1458 y 2316 del Código Civil. Dicho marco teórico concibe esta acción restitutoria como una expresión del principio del enriquecimiento injustificado en nuestro ordenamiento jurídico, que contrasta

101 En este sentido, señala Peter Birks: "Las indemnizaciones compensatorias fácilmente alcanzan cientos de libras incluso sin agregar elementos agravados ni mucho menos punitivos". BiRKs (1992), p. 80. Adicionalmente, cabe recordar que para algunos autores estas acciones pueden ser justificadas sobre la base de la justicia correctiva. Véase más arriba nota 28.

102 Sin perjuicio de la inconstitucionalidad estimada por el Tribunal Constitucional en la sentencia antes citada. Tribunal Constitucional, Rol No 2.437, de 14 de enero de 2014, c. $36^{\circ}$ y ss. 
con la postura adoptada por la Corte Suprema en los casos Inverlink, según la cual se trataría de una hipótesis de carácter excepcional. En las secciones anteriores se plantea que, incluso sin la necesidad de una reforma legal sobre la materia, es posible argumentar la existencia de acciones restitutorias de ganancias obtenidas ilícitamente. En este contexto, es clave la labor tanto de la doctrina como de la jurisprudencia chilenas para plantear estas acciones y discutir los requisitos de procedencia para cada una de ellas. En este contexto, la acción restitutoria de los artículos 1458 y 2316 no sería más que una de estas acciones cuyo fundamento normativo reside principalmente en la prevención o disuasión, y no en la justicia correctiva.

Ahora bien, la procedencia de estas acciones restitutorias no se encuentra exenta de objeciones y problemas que deben resolverse coherentemente con el resto de las acciones disponibles en el ámbito del derecho civil. Espero haber resuelto uno de estos problemas, que tiene que ver con la concurrencia de estas acciones restitutorias con acciones indemnizatorias. Mi propuesta de evitar el doble pago es coherente con el fundamento de justicia correctiva de la acción indemnizatoria y con la solución adoptada en el sistema inglés. La solución se sustenta, además, positivamente en la Ley No 19.039, de 1991. Sin embargo, otros problemas no fueron discutidos en el presente trabajo. Solo puedo mencionar aquí, pero no discutir, dos de estos problemas. El primero de ellos tiene que ver con la restitución de ganancias obtenidas como consecuencia de un incumplimiento contractual. El fundamento normativo que justifica establecer esta acción reside en la prevención o disuasión, es decir, en prevenir que las partes incumplan los contratos en general. No obstante lo anterior, para el análisis económico del derecho ello es un error. Para quienes plantean la doctrina del "quiebre eficiente del contrato", el sistema jurídico debe establecer mecanismos que precisamente faciliten a las partes incumplir los contratos, siempre que ello sea eficiente. ${ }^{103}$ Se trata, en consecuencia, de un asunto respecto al cual el sistema jurídico debe elegir entre adoptar normas que faciliten los incumplimientos eficientes de los contratos, basado en el fundamento normativo del análisis económico del derecho, o establecer mecanismos como la restitución de ganancias obtenidas como consecuencia

${ }^{103}$ De acuerdo a Cooter y Ullen, "el incumplimiento es más eficiente que el cumplimiento cuando los costos del cumplimiento superan a los beneficios de todas las partes. Los costos del cumplimiento superan a los beneficios cuando ocurre una contingencia que vuelve a los recursos necesarios para el cumplimiento más valiosos en un uso alternativo". COOTER y Ulten (2000), p. 238. Entre nosotros, un partidario de esta doctrina es Rodrigo Barcia Lehmann, quien sostiene que "el Derecho debe permitir que el deudor pueda darle un destino más eficiente a la cosa adeudada, mediante la negociación con un tercero, que podría ser, por ejemplo, un segundo comprador, y compensar al acreedor" adecuadamente. BARCIA (2004), p. 143. 
de incumplimientos contractuales, para efectos de prevenir que las partes incumplan los contratos. ${ }^{104}$

En segundo lugar, un problema que debe resolverse tanto en el ámbito de las acciones restitutorias por incumplimiento contractual como en aquellas derivadas del uso indebido de propiedad ajena, consiste en determinar en qué medida las ganancias obtenidas por el demandado están causalmente conectadas con el hecho ilícito, y en qué medida dichas ganancias se deben al esfuerzo o trabajo propio del demandado. ${ }^{105}$ En nuestros ejemplos, ¿en qué medida fue el esfuerzo de Pedro el que le permitió ganar \$ 100 con la carrera del caballo Rocinante que pertenecía a Juan? Asimismo, ¿en qué medida fue el esfuerzo de Carlos el que le permitió venderle a Pep-Cola la fórmula secreta de Cola-Cola? (Suponiendo, para estos efectos, que Carlos negoció un monto alto para vender la fórmula, y que quizá Cola-Cola no habría obtenido ese monto en caso de haber vendido ellos mismos la fórmula). Sin duda, se trata de una investigación causal que se vislumbra compleja.

\section{Bibliografía CitADA}

Alessandri Rodríguez, Arturo (1943): De la Responsabilidad Extracontractual en el Derecho Civil Chileno (Santiago, Editorial Jurídica de Chile).

Aristóteles (2008), Ética Nicomaquea (Traducc. Julio Pallí Bonet, Barcelona, Del Nuevo Extremo/ Gredos).

BANFI del Río, CRISTIÁN (2012): “Por una reparación integral del daño extracontractual limitada a los hechos dolosos o gravemente negligentes", en: Revista lus et Praxis (año 18, № 2), pp. 3-32.

Barcia Lehmann, Rodrigo (2004): Los Efectos de las Obligaciones desde la Perspectiva del Análisis Económico, en: Pizarro Wilson, Carlos (editor), Cuadernos de Análisis Jurídicos: Colección de Derecho Privado, Tomo I: Temas de Responsabilidad Civil (Santiago de Chile, Ediciones Universidad Diego Portales).

${ }^{104}$ Cabe señalar que para Katy Barnett, en el common law los disgorgement damages no serían necesariamente un obstáculo para el quiebre eficiente del contrato, ya que en los casos de reventa debiera ser requisito para que proceda la restitución de ganancias que el objeto del contrato sea difícil de reemplazar. BARNETT (2012), pp. 67-72.

105 Este problema también se presenta para la hipótesis del artículo 108 letra b) de la Ley № 19.039, de 1991, cuando establece como mecanismo de cálculo para determinar la indemnización de perjuicios respectiva, las utilidades obtenidas "como consecuencia de la infracción". ¿En qué medida las utilidades obtenidas por el infractor se generaron como consecuencia de la infracción y no por el esfuerzo propio del infractor? 
BARKer, Kit (2014): “'Damages Without Loss': Can Hohfeld Help?", en: Oxford Journal of Legal Studies, (No 34), pp. 1-28.

Barnett, Katy (2012): Accoounting for Profit for Breach of Contract (Oxford, Hart Publishing).

Barros Bourie, Enrique (2006): Tratado de Responsabilidad Extracontractual (Santiago, Editorial Jurídica de Chile).

Benson, Peter (2004): "Disgorgement for Breach of Contract and Corrective Justice: An Analysis in Outline", en: NeYers, Jason et al. (eds.), Understanding Unjust Enrichment (Oxford, Hart Publishing).

— (1992): "Civil Wrongs: A New World", en: Buttersworths Lectures 19901991 (London, Buttersworths).

BIRKS, Peter (2003): Unjust Enrichment (Oxford, Oxford University Press).

Bottrell, Andrew (2010): "Contractual Performance, Corrective Justice, and Disgorgement for Breach of Contract", en: Legal Theory, № 16, pp. 135-160.

Burrows, Andrew (2007): The Law of Restitution, $3^{\text {a }}$ edición (Oxford, Oxford University Press).

Cartwright, John (2013): Contract Law. An Introduction to the English Law of Contract for the Civil Lawyer, $2^{a}$ edición (Oxford, Hart Publishing).

Chadwick Valdés, Tomás (1933): "De la naturaleza jurídica del dolo", en: Revista de Derecho y Jurisprudencia Tomo 36, primera parte ( $\left.N^{\circ} 5-6\right)$, tomo 36, pp. 65-107.

Coleman, Jules L. (1992a): "Tort Law and the Demands of Corrective Justice", en: Indiana Law Journal ( $\left.N^{\circ} 67\right)$, pp. 349-379.

_ (1992): Risks and Wrongs (New York, Cambridge University Press).

CoOter, Robert y Uleen, Thomas (2000): Law and Economics (Reading, Adison Wesley Longman).

CorRal TAlCIANI, Hernán (2010): Contratos y daños por incumplimiento (Santiago, Editorial Abeledo Perrot-LegalPublishing).

- (2013): Lecciones de responsabilidad extracontractual, segunda edición (Santiago, LegalPublishing).

Descheemaeker, Eric (2009): The Division of Wrongs. A Historial Comparative Study (Oxford, Oxford University Press).

Domínguez Águila, Ramón H. (2009): "Sobre el artículo 2316 inciso segundo del Código Civil y la acción contra el que recibe provecho del dolo ajeno", en: Revista de Derecho Universidad de Concepción ( $\left.N^{\circ} 225-226\right)$, pp. 217-230. 
Domínguez Hidalgo, Carmen (1998): "La indemnización por daño moral. Modernas tendencias en el derecho civil chileno y comparado", en: Revista Chilena de Derecho (№ 25), pp. 27-55.

Domínguez Hidalgo, Carmen (2000): El daño moral (Santiago, Editorial Jurídica de Chile).

Edelman, James (2002): Gain-Based Damages. Contract, Tort, Equity and Intellectual Property (Oxford, Hart Publishing).

FinNIS, John (2000): Ley natural y derechos naturales (Traducc. Cristóbal Orrego Sánchez, Buenos Aires, Abeledo-Perrot).

FriedmanN, Daniel (1980): "Restitution of Benefits Obtained through the Appropriation of Property or the Commission of a Wrong", en: Columbia Law Review ( No 80), pp. 504-558.

FueYo LANERI, Fernando (1990): Instituciones de Derecho civil moderno (Santiago, Editorial Jurídica de Chile).

Gardner, John (2011): "What is Tort Law for? Part 1. The Place of Corrective Justice", en: Law and Philosophy ( $\left.\mathrm{N}^{\circ} 30\right)$, pp. 1-50.

GoldBerG, John CP y Zipursky, Benjamin (2010): "Torts as Wrongs", en: Texas Law Review ( No 88), pp. 917-986.

Gordley, James (2006): Foundations of Private Law. Property, Tort, Contract, Unjust Enrichment (New York, Oxford University Press).

Kronman, Anthony T.: "Specific Performance", en: The University of Chicago Law Review ( ${ }^{\circ}$ 45), pp. 351-382.

LOCKE, John (1997): Dos ensayos sobre el gobierno civil (Traducc. Francisco Giménez Gracia, Madrid, Espasa).

Peñallillo Arévalo, Daniel (1996): "El enriquecimiento sin causa. Principio de derecho y fuente de obligaciones", en: Revista de Derecho Universidad de Concepción (Nº 200), pp. 7-40.

Peñallillo Arévalo, Daniel (2010): Los bienes: la propiedad y otros derechos reales, $4^{a}$ edición para estudiantes (Santiago, Editorial Jurídica de Chile).

PizArRo Wilson, Carlos (2009): "La acción de restitución por provecho de dolo ajeno", en: Estudios de Derecho Civil IV (Santiago, LexisNexis), pp. 679-688.

POtHIER, Robert Joseph (2003): Tratado de las Obligaciones (México DF, Tribunal Superior de Justicia del Distrito Federal).

RiPSTEIN, Arthur (2004): "Authority and Coercion", en: Philosophy \& Public Affairs ( No 32), pp. 2-35.

SteVens, Robert (2007): Torts and Rights (Oxford, Oxford University Press). 
WeINRIB, Ernest J. (2012a): The Idea of Private Law, $2^{\text {a }}$ edición revisada (Oxford, Oxford University Press).

WeInRIB, Ernest J. (2012b): Corrective Justice (Oxford, Oxford University Press). WRIGHT, Richard W. (1992): "Substantive Corrective Justice", en: lowa Law Review (No 77), pp. 625-711.

Zimmermann, Reinhard (1990): The Law of Obligations. Roman Foundations of the Civilian Tradition (Cape Town, Juta \& Co).

\section{JURISPRUDENCIA CITADA}

Estados Unidos: Edwards v Lee's Administrator (1936), Court of Appeals of Kentucky, 5 de junio de 1936, 96 S.W. 2d 1028.

Reino Unido: Wrotham Park Estates Ltd. v Parkside Homes Ltd. (1973), Chancery Division, 19 de octubre de 1973 [1974] 1 WLR 798.

Estados Unidos: Snepp v United States (1980), United States Supreme Court, 19 de febrero de 1980, 444 U.S. 507, 62 L.Ed.2d 704.

Reino Unido: Attorney-General v Blake (2000), House of Lords, 27 de julio de 2000 [2001] 1 AC 268.

Ruiz Ruiz con Laboratorio Biológico S.A. (2001): Corte Suprema 5 de noviembre de 2001 (casación en la forma y en el fondo) en: Revista de Derecho y Jurisprudencia y Gaceta de los Tribunales № 4, pp. 234-242.

Reino Unido: Esso Petroleum Company Limited v Niad Limited (2001), Chancery Division, 22 de noviembre de 2001 [2001] EWHC Ch 458.

Corporación Nacional de Fomento de la Producción con Energas S.A. (2013): Corte Suprema 30 de septiembre de 2013, Rol No 4871-2012 (restitución de lo obtenido por provecho del dolo ajeno).

Corporación Nacional de Fomento de la Producción con I. Municipalidad de La Pintana (2013): Corte Suprema 30 de enero de 2013, Rol No 6302-2010 (restitución de lo obtenido por provecho del dolo ajeno).

Astudillo Capetillo, Milton con Compañía Minera Teck Quebrada Blanca S.A. (2014): Tribunal Constitucional 14 de enero de 2014, Rol No 2.437 (inaplicabilidad por inconstitucionalidad).

Javier Moya Cucurella y otros (2014): Corte de Apelaciones de Santiago 2 de diciembre de 2014, Rol No 2227-2013 (recurso de casación en la forma y apelación).

\section{NORMAS JURÍDICAS CITADAS}

Ley No 19.039, Ley de Propiedad Industrial. Diario Oficial 25 de enero de 1991. 